\title{
Covid-19: the place for women in pandemic response in the EU
}

\author{
Antonella Zarra $^{*}$ and Matilde Ceron ${ }^{\dagger}$
}

\begin{abstract}
Early research has highlighted the strongly gendered impact of the Covid-19 pandemic. Women have been disproportionately penalized because of sectoral segregation (e.g. tourism and services facing closures and healthcare and education subjected to high risk of exposures and disruptions) and an increased burden of childcare, pushing many out of the labor market. As a result, recent progress in terms of parity have come to an abrupt halt if not reversal during the pandemic, implying a dire need to mainstream gender parity concerns into countries' recovery efforts. Against such a backdrop, the question remains of the extent to which gender equality has been salient in the post-pandemic reconstruction and the extent to which such attention may be heterogeneous across countries. The European Union (EU) provides a welldefined case to assess such questions through its commonly financed recovery plan Next Generation EU (NGEU), which is designed - under common priorities including gender equality - at the Member State level and encapsulated into official documents: the National Recovery and Resilience Plans (NRRPs). Our analysis exploits such features for a crosscountry comparison of the saliency of gendered concerns within the EU. We employ a mixed method approach which complements assessment through automated text analysis on the corpus of the 25 available national plans with qualitative analysis of four case studies to confirm and deepen the quantitative findings. The frequency, dictionary analysis and structural topic modelling (STM) confirm limited saliency of gender parity within national recovery investment and reform strategies. Substantial geographical differences do, however, emerge, to some extent favoring countries which already displayed higher levels of sensitivity to gender equality ahead of the pandemic. The qualitative analysis confirms such patterns. Our results highlight the risks of limited mitigation to the damages to gender equality the pandemic has enacted. Our work points additionally toward heterogeneity, with especially limited saliency in contexts in which pre-existing gaps are the largest and mitigation limited in the early phase of the outbreak, implying a potentially widening divide in terms of equality in the aftermath of Covid-19 even within the EU.
\end{abstract}

Keywords: Covid-19; gender equality; European Union; Next Generation EU; topic modeling; text analysis.

\footnotetext{
* Institute of Law and Economics, Hamburg University, antonella.zarra@gmail.com

${ }^{\dagger}$ Department of Political and Social Sciences, University of Pavia, matilde.ceron@ coleurope.eu
} 


\section{Introduction}

Gender gaps in multiple arenas spanning from the workplace to political participation are welldocumented in the European Union (EU). Despite long standing efforts and progress over the years equality remains far from reach within the Member States. The Covid-19 health crisis has further exacerbated pre-existing cleavages resulting in a burden - especially in relation to childcare - which has predominantly fallen on women's shoulders. Research abounds on the pandemic and its negative implication for gender parity. On one side, there is the overrepresentation of women in certain sectors, including essential workers in healthcare and education but also others such as tourism and services frozen by lockdowns. On the other, there is the under-representation of women among decision-makers. Against this background, countries differ over their pandemic management and the (over) reliance on measures such as school closures and stay at home restrictions which come with increased risk for women of separation from the labor market or exposure to gender-based violence within the household. As a result, in the absence of corrective measures, the pandemic hence runs the concrete threat of halting and reversing the progress toward gender equality in recent years.

Under such premises, questions remain on the extent to which Covid-19 policy responses across countries have taken into account the gendered implications of the outbreak in crisis management and deployed adequate mitigation factors and the extent to which gender equality is prioritized in the recovery and post-pandemic reconstruction. To this purpose, the analysis assesses the saliency of gender equality within the post-pandemic recovery of the EU Member States through a mixed methodological approach. On the one hand, it performs a quantitative text analysis of the National Recovery and Resilience Plans (NRRPs) under Next Generation EU (NGEU), on the other, it selects four heterogenous EU Member States to conduct a casestudy investigation on how and if gender has shaped different policy responses. The article applies two complementary analytical approaches to examine the evolution and strength of the recovery efforts with regard to gender issues. First, it performs a hybrid quantitative analysis to recover information from NRRPs applying standard text mining techniques such as keywords analysis. Then, it extracts and processes data from the 25 available National Plans by means of unsupervised machine learning, and it runs a structural topic model (STM) to identify in a systematic manner salient topics related to gendered concerns and policies within the plans. By identifying latent topics of interest in the recovery plans, the analysis helps pinpoint the underlying gendered implications of the chosen national reform and investment priorities. Based on the findings, the paper presents a scoreboard of countries' performance in gender salience within the NRPPs highlighting geographical differences across the EU. Furthermore, in considering in-depth case studies of selected heterogenous Member States, the paper further expands the assessment of the plans comparing the pre-existing context toward gender equality together with national choices over Covid-19 containment and economic measures in the early months of the pandemic.

Having developed a comparative gendered assessment of the recovery efforts, the analysis considers how the place for women in the Covid-19 response relates to that of women leadership within societies and in pandemic decision-making. Do countries more advanced in the path toward equality perform better? Is that the case for a more substantial involvement of women leadership in crisis-management and decision making with regards to NGEU recovery plans? To this end, the paper considers the pre-existing progress toward gender equality along the dimensions of economic empowerment and representation, controlled for in the quantitative analysis and explicitly explored within the qualitative case studies. Results support that 
geographical differences parallel - to a certain extent - pre-pandemic divides: those countries for which gender is more salient within the NRRPs and in Covid-19 responses more in general are also the ones with more equal economies and higher gender representation.

The contribution of the analysis allows to draw preliminary insights on how a recovery plan with common priorities including gender parity translates into diverse salience of equality across the EU at the Member State level. The implication of our results is worrisome for convergence towards equal societies. The latter may be a transversal objective of NGEU and more broadly EU policies but its application in practice is inconsistent at best. The dynamics of heterogeneous saliency additionally points in a direction of the pandemic leaving behind a legacy of further divergence in the trajectory toward gender parity: countries with pre-existing substantial gaps in the economic and political arena may especially lag behind in prioritizing mitigation measures in their recovery strategies. The analysis points toward the importance of research on the gendered implication of Covid-19 policy choices and countries' existing strategies which - as in the case of NGEU - may shape economies and societies for the foreseeable future, contributing or hindering progress towards equality. Additionally, the divide along the fault line of pre-existing gender gaps supports the need for further research on the contribution of political representation in helping shape a reconstruction pathway that is more sensitive to the needs and the inclusion of women.

\section{Literature review}

\subsection{The gendered impact of the Covid-19 pandemic}

The existing literature has identified three main gendered issues that have been particularly relevant during the Covid-19 pandemic and the subsequent recession, namely women participation in the workforce and increased burdens from childcare and housework, the exacerbation of domestic violence and the lack of gender balance in decision-making processes.

When it comes to the labor market implications, women have been impacted in a twofold manner. On the one hand, the closure of economic activities during lockdown periods has affected sectors with a high percentage of female employment. On the other, social distancing and the closure of schools has increased the burden of housework and childcare for women. With regard to the latter aspect, during the spring and - at least for some countries - the fall of 2020, millions of school-aged children were left to the full responsibility of parents, who could not count on grandparents' or external support. According to a report by the JRC (Blaskò et al 2020) traditional gender norms that expect women to be caregivers and men to be breadwinners are still persisting in the majority of EU countries, and such a trend has been exacerbated by the pandemic.

A growing number of studies have analyzed changes in parents' caregiving responsibilities during the outbreak of Covid-19. Several lines of evidence (see inter alia Adams-Prassl et al. 2020; Collins et al. 2020; Cowan 2020; Farre et al. 2020; Frodermann et al. 2020; Kristal and Yaish 2020; Montenovo et al. 2020; Hupkau and Petrongolo 2020) suggest that during the first and second wave of Covid-19 women, and in particular mothers, have been more likely to exit the workforce and have decreased their work hours compared to men. For instance, in Germany women are reducing paid work hours and are more worried about childcare work, while men are more concerned about paid work (Czymara et al. 2020). Alon et al. (2020) showed that the 
economic recession caused by the pandemic has impinged more severely on sectors with a high participation of women in the workforce. Along the same lines, A survey conducted in Italy during the first wave of the outbreak confirmed that work from home arrangements and housework responsibilities have fallen to women (Del Boca et al. 2020). In the same vein, as reported by Farre et al (2020), in Spain, women were more likely to work from home than men and carried most of the burden from housework and childcare during the spring lockdown. Unlike previous recessions, the current crisis exacerbated gender inequality in paid and unpaid work in the short-term, harming female labor market prospects.

However, preliminary research from the UK (Sevilla and Smith 2020), Spain (Farré and Gonzalez 2020) and Italy (Del Boca et al. 2020), shows that the pandemic has partially led to a shift towards a more equal allocation of duties between partners. According to Adams-Prassl et al. (2020), real time survey results from the UK, US and Germany indicate that, despite a considerable variation among countries with regard to the impact of the pandemic on labor markets, women and less educated workers are in general more affected by the crisis and that smart working provisions have harmed more severely women than men. When it comes to job loss probabilities, while gender matters in the US and UK, in Germany gender does not predict significant job loss.

Other evidence (Reichelt Makovi and Sargsyan 2020) from the US, Germany and Singapore reiterates similar messages, namely women are more subject to unemployment, reduction in working hours and transition to smart working and that gender-role attitudes change according to the employment status of female and male partners. In particular, female partners who became unemployed during the crisis showed a more traditional attitude, while male partners who became unemployed displayed a more egalitarian mindset.

In addition, Mongey and Weinberg (2020) point out that since women are more likely to be employed in "high work-from-home" and "high physical-proximity" sectors, their working conditions might be less affected by social distancing policies in the short term. Nevertheless, this might result in a more difficult integration into the economy at a later stage. A further interesting contribution (Bertocchi 2020) sheds light on the level of exposure to the disease within segments of the population and finds that working-age women in Italy are more susceptible to SARSCov-2 than working-age men, most likely because of the female overrepresentation in healthcare and education jobs, which expose them to a higher risk of contagion.

A second consequence of the Covid-19 outbreak concerns the general increase in the level of violence against women. The pandemic has forced millions of people to stay at home, either in quarantine or in forced lockdowns, impairing the domestic equilibrium for many families and contributing to an increase in the risk of gender-based abuse. In fact, the fear and uncertainty experienced during these forced quarantine periods has been an enabling factor for the exacerbation of violence. According to the European Parliament, during the first wave, cases of domestic violence have risen by a third in some EU countries. Countries have reacted to this emergency in different ways. For instance, Spain launched a national plan and has been strengthening coordination among health, judicial and police authorities. In France, during the spring lockdown, a provision supported women who were experiencing abuses at home with an alternative accommodation. Many countries have adopted legislation to make hotlines and shelter essential services (EIGE 2020). However, the pandemic shed light on a shaky support system for women exposed to domestic abuses. 
A third element of concern in the assessment of the gendered impacts of the pandemic is the involvement of women in strategic decisions that affect them directly. The UN Gender Social Norms Index (UNDP 2020) reports that the majority of men and women around the world consider men better political leaders than women. This misconception is reflected in the scarce descriptive and substantive representation of women in parliaments and leading institutions globally. Unfortunately, the imbalance is reflected also in the fight against Covid-19. In fact, although women are more likely to comply with restraining measures such as social distancing and, compared to men, they tend to perceive the pandemic as a serious problem (Galasso et al, 2020), their leadership skills during the Covid-19 crisis are far from being taken into account. The glass ceiling keeps female experts away from any managerial role. Women have been excluded from decision making bodies established specifically for Covid-19. For example, in Italy, during the spring of 2020, the government established two main strategic bodies in charge of containing the contagion while designing post pandemic measures. On the one hand, the Scientific Technical Committee (Comitato Tecnico Scientifico) gives advice to the head of the Civil Protection Department on the adoption of prevention measures necessary to cope with the spread of the virus. On the other hand, the Committee of Experts in Economic and Social Issues (Comitato di esperti in materia economica e sociale) was established to lead the post Covid-19 reconstruction. The former body was made exclusively by men while the latter included members, of which only four were women. Women interest groups voiced their dissent and were able to stir the debate toward the need to include them in such decision-making bodies, resulting in more balanced task forces. However, a more balanced descriptive representation does not seem to have impacted the policy outcomes of the reconstruction reforms, where gender parity remains a neglected topic.

\subsection{The case of the common EU Covid-19 response: NGEU, the NRRPs and gender parity}

Against the backdrop of the gendered implications of the pandemic, the EU response offers a well-defined case for the cross-country comparison of the saliency of equality concerns in the recovery. Indeed, following an initial period in which countries within the EU were fully left on their own to sustain their economy through the crisis and fuel the reconstruction, after months of divisive negotiation a common recovery instrument found a political agreement in July 2020. On such a basis, NGEU and specifically its financing instrument consisting of the Recovery and Resilience Facility (RFF) underwent a lengthy legislative process requiring not only the greenlight of the EU institutions but also ratification of the national Parliaments. Its complex form, however, is of value given that priorities - including the transversal one of gender equality - for a green, digital and inclusive recovery are defined within NGEU and hence should generally direct those of all EU Member States. However, especially in their inclusion component, they are not associated with spending targets. In parallel, the precise structure and priorities of the recovery are defined at the country level as countries devised their NRRPs to submit to the approval of the Council. The timeline for such a process foresees a final deadline for official submission of 30 April 2021, which was, however, not respected by all Member States. Nevertheless, as of 31 August 2021 all countries except Estonia and the Netherlands had submitted their NRRPs to the Commission. In view of the architecture of the NRRPs, the exact saliency of given themes especially in the social arena - as a minimum of $20 \%$ of allocation is reserved for digitalization and 37\% for sustainability - may vary across the Member States. As a consequence, while Member States are instructed to consider gendered implications when developing their plans, the extent to which equality is salient within the NRRPs is primarily a matter of national priorities and preferences. 
At the EU level, gender has long been the subject of a mainstreaming effort by the Commission. Currently, the Gender Equality Strategy 2020-2025 drives EU policy on the matter, complementing mainstreaming with intersectionality as horizontal principles guiding its implementation (COM/2020/152 final). Its objectives are five-fold. The first three - (1) Being free from violence and stereotypes; (2) Thriving in a gender-equal economy; (3) Leading equally throughout society - reflect specific areas of policy intervention which can be summarized respectively as dedicated to the area of gender-based violence, economic empowerment and political representation. Two further points - (4) Gender mainstreaming and an intersectional perspective in EU policies and (5) Funding actions to make progress in gender equality in the EU - reflect its implementation stage which beyond the financing of the strategy stresses indeed the two above-mentioned horizontal principles. Such an approach has been expanded to NGEU. In this context, the commonly defined priorities within the NGEU regulatory framework foresee the mainstreaming of gender equality. The RRF Regulation (Regulation (EU) 2021/241) refer to gender in recital 28 which - acknowledging the uneven burden of the pandemic on women - calls for gender-mainstreaming within the plans. Additionally, specific reference is made to mitigating investment such as that in care infrastructure. Recital 39 likewise calls for the detailing of expected contributions to gender equality within the NRRP, which is also recalled in article 4 among the elements for the Member States to include for the plan to be "duly reasoned and substantiated". Nevertheless, progress on gender parity remains heterogeneous across the Member States. According to the WEF (2021) Global Gender Report at the top extreme there's a country like Finland having closed $86 \%$ of the gender gap overall and over $80 \%$ in the economic arena, while conversely countries like Hungary and Greece stop at 69 and $68 \%$ respectively, likewise lagging substantially behind in the arena of economic participation with a gap filled only for $67 \%$. As a result, it remains to be seen the extent to which - given the reversal of progress in the pandemic - gender parity is salient among the priorities for the post Covid-reconstruction within the NRRPs and the extent to which it reflects pre-existing sensitivity to equality or conversely substantial gaps to mitigate

\section{Data and methods}

The core of the analysis encompasses the text of the NRRPs officially submitted by the end of August 2021 to the European Commission. Additional sources other than the plans themselves are included for specific purposes as illustrated in the remainder of this section, both in the identification of the main gendered themes to evaluate the plans against and in supporting their in-depth assessment for selected case studies. The methodology complements a quantitative approach based on automated text analysis of the primary sources, with a qualitative in-depth comparison of four selected Member States, chosen in light of their different approaches in tackling gender imbalances in the post-pandemic reconstruction.

The corpus for the quantitative analysis includes $25 \mathrm{NRRPs}^{1}$, which were translated to English beforehand, across 40 documents given that in some instances multiple documents constitute the official plan. The translation has been carried out through the eTranslation tool provided by the European Commission, in line with previous work employing text in the multilingual

\footnotetext{
${ }^{1}$ Estonia and the Netherlands are excluded as their NRRPs are unavailable as they have not yet been officially submitted to the European Commission. The 25 NRRPs officially submitted are indicated by the European Commission Recovery and Resilience facility here: https://ec.europa.eu/info/business-economy-euro/recoverycoronavirus/recovery-and-resilience-facility en
} 
context of the EU (e.g. Lucas et al. 2015, Rauh et al., 2020, Traber et al., 2020) which have been assessed to yield results as good as human translation - in a bag-of-words context - even through the use of a far less advanced method as Google translation (deVries et al., 2018, Reber, 2019).

Table A1 provides a summary of the corpus, indicating the three additional document variables associated with the text: the geographical region (north $=1$, south $=2$ and eastern along with new Member States = 3), economic empowerment and political representation. The latter two are derived from the Global Gender Gap Report 2021 of the World Economic Forum (2021), referring respectively to the "Economic participation and opportunity" index and the one on "Political empowerment". The resulting corpus consisting of nearly 1.5 million sentences is processed generating 54000000 tokens from which punctuation and stop words are removed before proceeding to stemming through Porter's algorithm, which is the standard modality for text analysis. The resulting document-feature matrix $(\mathrm{dfm})$ is further cleaned from irrelevant words (e.g. also, make) and trimmed to exclude those appearing in less than five documents. Top features are generated to highlight the saliency of gendered keywords before turning to country level distinctions.

The dictionary analysis allows for the direct comparison of the salience of gender across the NRRPs. The dictionary analysis is grounded on an additional text analysis of the documents produced at the European Parliament level within the gender equality Committee (FEMM). Specifically, documents and press releases on NGEU and Covid-19, together with the amendments proposed by the MEPs on the RFF (i.e. the financing instrument behind the NRRPs) have been processed in order to detect key gendered themes of interest. The selection criteria for the documents to include allows not only for the direct perspective of the FEMM committee on gendering the NRRPs but also coverage of the key concerns raised in the context of the Covid-19 pandemic: on one side the challenge against women's economic empowerment represented, for example, by additional care responsibilities during lockdowns and on the other the increased risk of exposure to gender-based violence.

The documents included are:

- Covid-19 and its economic impact on women and women's poverty - Insights from 5 EU Countries; ${ }^{2}$

- The gendered impact of the Covid-19 crisis and post-crisis period; ${ }^{3}$

- Position in the form of amendments of the Committee on women's rights and gender equality; ${ }^{4}$

- Covid-19: Stopping the rise in domestic violence during lockdown. ${ }^{5}$

Alike for the classification then employed in the analysis of the NRRPs two levels of gendered keywords are identified distinguishing those unequivocally linked with women and equality concerns or policies (e.g. gender, maternity, mother, reproduction,...) from others generally used in conjunction with such concerns but less unambiguously linked with the topics of

\footnotetext{
${ }^{2}$ Study for the FEMM Committee - Executive summary https://www.europarl.europa.eu/RegData/etudes/STUD/2021/693183/IPOL STU(2021)693183(SUM01) EN.p $\underline{\mathrm{df}}$

${ }^{\frac{1}{3}}$ Study for the FEMM Committee

https://www.europarl.europa.eu/RegData/etudes/STUD/2020/658227/IPOL_STU(2020)658227 EN.pdf

${ }^{4}$ Amendments on the RRF regulation tabled by the FEMM committee

https://www.europarl.europa.eu/doceo/document/A-9-2020-0214_EN.html\#title8

${ }^{5}$ Press release of the FEMM committee https://www.europarl.europa.eu/news/en/pressroom/20200406IPR76610/covid-19-stopping-the-rise-in-domestic-violence-during-lockdown
} 
interest (e.g. household, leave, gap, discrimination,...). On such a basis a parallel distinction is put forward in the dictionaries, with one version only considering the former unambiguous keywords, while the second expanding the included terms to encompass also those with a weaker linkage with gendered concerns or policies.

To further consider the saliency of gendered concerns in the NRRPs the assessment proceeds with unsupervised text analysis through Structural Topic Modelling (STM) (Roberts et al 2014 and Roberts et al 2019), allowing to uncover latent key topics within the corpus. Unlike alternatives such as Latent Dirichlet Allocation (LDA), STM allows for covariates for the prevalence of topics across documents - namely in the case at hand the geographical region within the EU, women's economic empowerment and political representation - thus improving the accuracy of the model. In determining the number of topics for the model to estimate, we follow two criteria established within the literature in a context in which such a process is inherently arbitrary with limited convergence over the appropriate methodology (Roberts et al 2019). Firstly, we run the model through spectral initialization, setting the number of topics $(k)$ to zero hence determining the number through the algorithm by Lee and Mimno (2014). The result exceeds 100 topics, rendering interpretation problematic. Alternatively, we run multiple models comparing a manageable number of topics - spanning from 3 to 20 - over held-out likelihood, residuals and semantic coherence. As shown in FigureA1, after careful consideration and cross-validation, a final number of 12 topics was selected for the analysis.

For what concerns the qualitative side of the analysis, two methodological justifications arise, on one side concerning case selection and on the other on the focus of the analysis. On the first aspect, the four chosen Member States allow for geographical heterogeneity across core (France, Germany) and periphery (Italy, Spain), differing at the same time over their progress towards gender equality. The selection hence reflects the purpose of the case studies which is the deepening of the exploration of the patterns emerged in the text analysis with respect to cross-country heterogeneities in the levels of salience of gendered concerns. Additionally, the choice of the "big four" limits differences unlinked with gender preferences which arise because of the different scale of post-pandemic restructuring in the context of recovery which may be the case if including small countries. Finally, while NGEU priorities weak economies and those hit the most by the pandemic, implying magnitudes of differences between the resources allocated to the top beneficiaries of Italy and Spain, the inclusion of France and Germany which insert their NRRPs into ambitious nationally financed recovery plans redress to an extent such imbalances. In terms of the focus of the qualitative analysis, three areas are selected in view of the research questions at hand: (i) the mapping of the pre-pandemic gender equality context, (ii) the overall pandemic response in the Member States assessed through gendered lenses and (iii) an in-depth exploration of gender parity measures within the NRRPs. The approach allows to explore potential linkages suggested by the quantitative analysis against the benchmark of a big-picture portrayal of the sensitivity to gender parity ahead, during and in the aftermath of the pandemic.

\section{Results}

\subsection{Quantitative analysis of all available NRRPs}

The first step in the analysis evinces the gendered keywords through the reference documents illustrated in the previous section. The results which determine both the components of the dictionary and the benchmark for the classification of features as gendered throughout the 
analysis are presented in Table A2 in the appendix. Against such classification, the overall saliency of gendered themes can be assessed in the corpus as a whole. A visual representation is provided in Figure 1 below through the word cloud of the top 200 features in the $\mathrm{dfm}$. It is complemented in the appendix by the comprehensive display of the top 200 features according to our classification in Table A3 along with the representation restricted to the top 50 in Figure A2 which allows for immediate reference to the frequency of each term. Consistently, the prevalence of gendered keywords is limited. Only the mildly gendered feature of schools makes it into the top 50, expanded in the top 200 to include 7 further terms within the same category (e.g. school, families, household, care) and 2 strongly gendered terms (women, gender).

Even at the features level, the cross-country comparison reveals substantial differences, which align to some extent with the pre-pandemic scenario of heterogeneous equality gaps within the EU. Sweden and Spain are the only Member States whose top 25 features include keywords unambiguously associated with gendered concerns: women for both countries and gender for Spain. Beyond these two Member States a further distinction is among the 13 countries displaying at least one keyword more broadly associated with gendered issues (either care or school) and the remaining 10 which do not feature this theme at all. Specifically, Austria, Croatia, Czechia, Finland, Hungary, Latvia, Lithuania, Poland and Slovakia display care among their features while Ireland, Italy, Malta, Romania and Slovakia include school. The gendered feature is generally among the bottom five, with the exception of Austria, Czechia, Poland, Romania and Spain situating their gendered feature slightly above such a threshold.

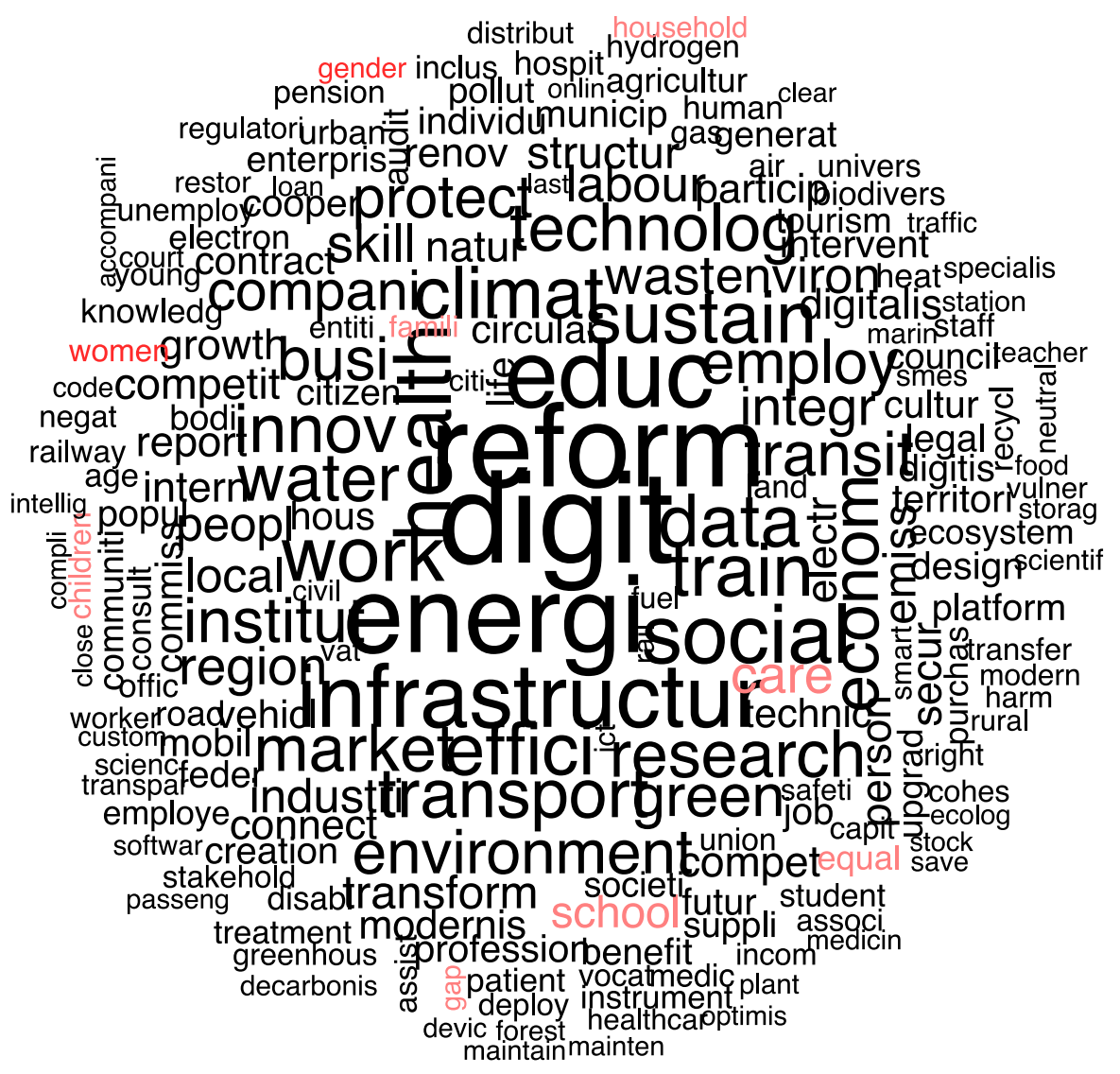

Figure 1 - Word cloud of gendered features in the top 200 
Conversely, Belgium, Bulgaria, Cyprus, Denmark, France, Germany, Greece, Luxembourg, Portugal and Slovenia do not display any gendered keyword among their most salient features. The picture is hence quite mixed regionally, with a transversal set of countries included in the ungendered group. The specific keyword emerging for those that do touch upon gendered concerns does, however, follow regional fault lines. Namely, Southern Member States never refer to care - implying potentially a high attention to services which directly support the access of mothers to the labor market - but rather schools. The sole exception is Spain with the highly gendered keywords which nonetheless do not refer potentially to care services. Schools can be considered among the most ambiguously gendered keywords as the in-depth qualitative assessment reveals the term can often link to infrastructural issues or those in connection with pandemic safety rather than directly calling into question dimensions which support women empowerment as, for example, gender parity in STEM or guaranteeing prolonged in-school services for children. Albeit far from conclusive there is hence an indication that countries with a stronger progress on parity - e.g. Spain and Sweden - may have given a higher saliency to core gendered themes within their plans while those in the South less sensitive to equality may have a less prominent attention which may capture predominantly keywords that are not necessarily linked with enabling policies.
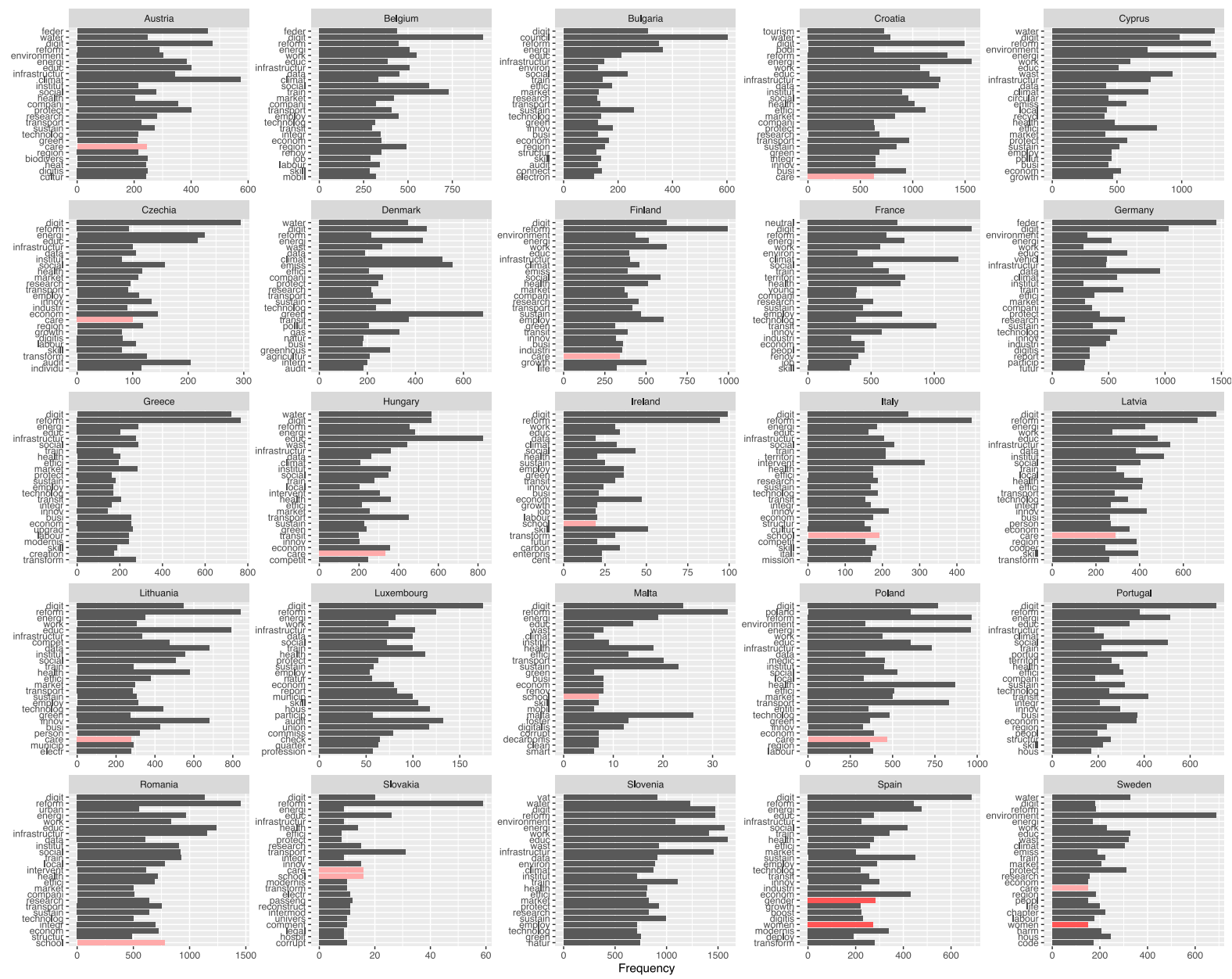

Figure 2 - Gendered features within the top 25 by country

Heterogeneity is further confirmed by the dictionary analysis, which supports also the distinction in ranking when considering "strong" indicators of gendered themes compared to the "weakly" associated features. The two as indicated in the methods sections are translated into two separate "strict" and "broad" dictionaries, which in Table A2 in the appendix are 
reflected respectively by dark and light pink as in the previous and all figures to follow. The dictionary equivalent is respectively "Gender" and "Genderbroad" in Figure 3 below, which shows the cross-country scoring of the dictionary analysis displaying the (weighted) proportion of gendered keywords among the NRRPs of each Member States. At the extremes, there is a fair overlap between the portrayal presented by the top features and by the dictionary analysis. For example, Luxembourg is among those without any gendered feature in Figure 2 confirmed by the dictionary analysis as dedicating a nearly non-existent proportion of their NRRP to gender-related themes, even in the broadest term. Belgium, Bulgaria, Cyprus, Denmark, France, Germany followed suit in terms of their position in the dictionary analysis corresponding to the no gendered keyword emerging in Figure 2. The group in the dictionary includes, however, also Croatia and Finland which do have a gendered keyword (care) albeit at the bottom of their top 25. At the opposite extreme, we do see some correspondence between the top rankers in Figure 2 and 3, Spain and Sweden, which are indeed among those with the highest prevalence especially of gendered themes defined restrictively. The latter element brings forward a further point: while Spain, for example, scores highly on both dictionaries, the broad one sees a more limited correspondence both with the feature analysis and the gender parity scoring of the countries by the WEF report. Indeed, the highest result is detained by Slovakia, far from shining in terms of the restricted assessment. Similarly, even countries like Greece which do not appear positively through the feature analysis score highly in the broad gendered dictionary including non-unambiguous terms (e.g. school, care). Another case of substantial distinction between the two dictionaries is Slovakia registering the higher score on the broad side while situating itself squarely on the other extreme in the restricted version.
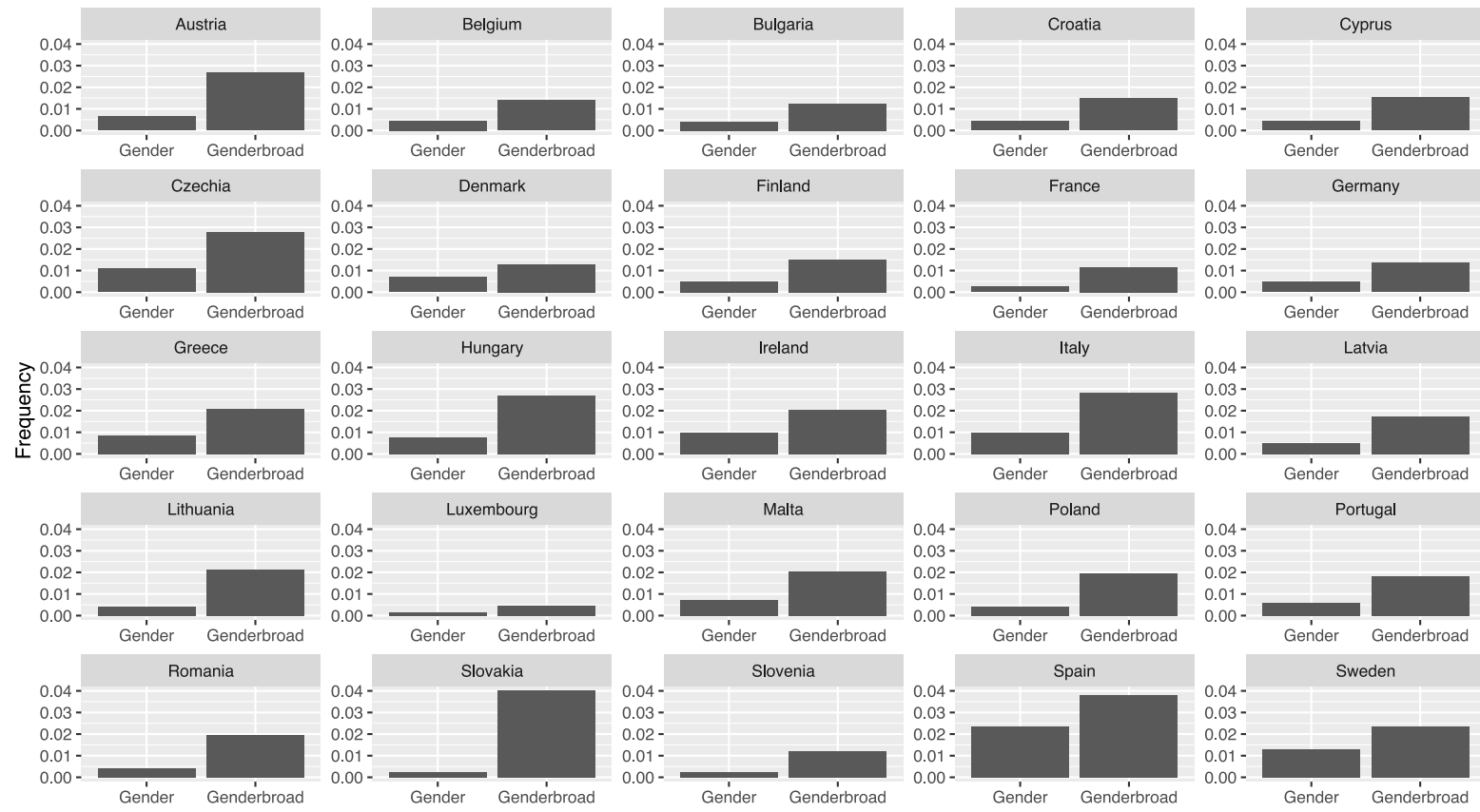

Figure 3 - Dictionary analysis

Table A4 shows the numeric scores both in absolute terms and using the weighted dfm on which the previous figure is based. Each column is scored as a heatmap showing a gradient from white to dark pink which reflects the relative scoring in terms of the dictionary analysis. The table allows for a precise ranking of countries performance, confirming, however, both the sensitivity of the scoring in absolute terms to the length of the text - hence supporting the preference for a weighted $\mathrm{dfm}$ - and the heterogeneity across the broad and restricted assessment. The implication is that inclusiveness in this arena introduces some limitation on 
reliability. Hence the most robust picture is that provided by the restricted keyword analysis which is near universal in depicting the limited salience of gender in the NRRP and gives a consistent primacy to countries that have a previous positive track record in the area of equality. Nevertheless, as the limited saliency in other Scandinavian countries suggest, sensitivity to gender parity does not appear as a sufficient condition for mainstreaming of gender in the postpandemic recovery strategy.

The STM model, on the basis of the methodological considerations illustrated in section 3, is presented in Figure 4 through the topic shares. Table A5 in the appendix shows the top ten highest probability words across the topics. Both characteristics indicate the challenge of uncovering well-defined topics against which to categorize the different priorities and investments within the NRRPs. The qualitative analysis of the plans of the four selected case studies confirm such a challenge reflects the structure of the documents as cross-references to priorities under different pillars (e.g. the social or environmental implication of an investment for digitalization) are pervasive, hence indicating strong cross-linkages across different policy areas which are then reflected by the unsupervised text analysis. Indeed, the level of overlap is extensive across the 12 topics, a clear limitation of the model which remains across alternative specifications both of topic numbers and covariates.

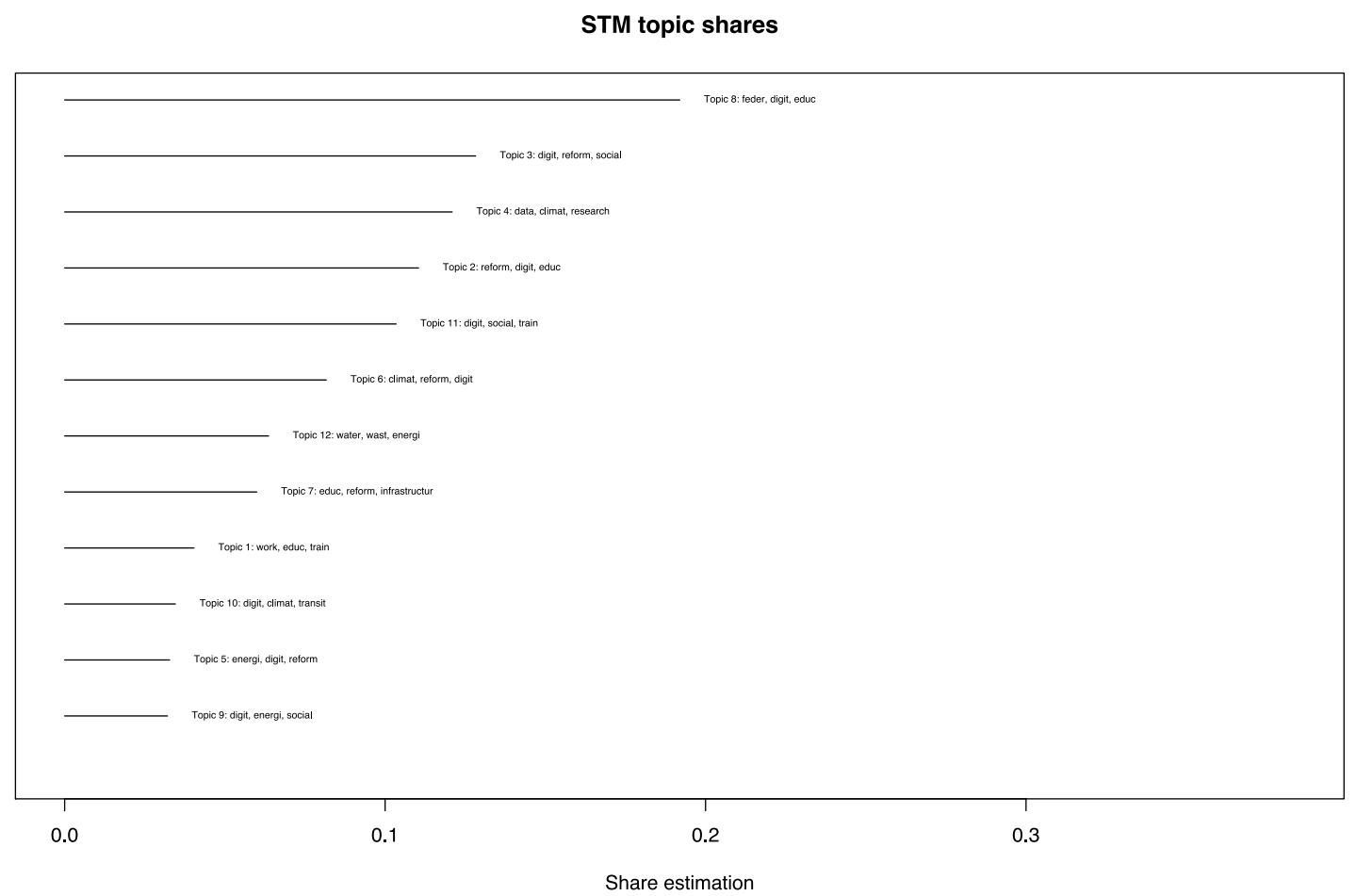

Figure 4 - STM topic shares

Nevertheless, the unsupervised classification remains of use for the research question at hand, specifically in relation to the saliency of gendered concerns. Indeed, considering the top 10 across all 12 topics displayed in Table A5, one single gendered keyword emerges: school. Such a word has already been assessed earlier as being non-unequivocally linked with gendered concerns and policies, hence reflecting one of the weaker signals (e.g. within the broad dictionary) of sensitivity to parity. Against this benchmark, Figure 5 further explores the components of the most prevalent topic (Topic 8) which is the one at the same time displaying the (mildly) gendered keywords of schools. The mapping indicates that while their relative 
weight is minor compared to the primary loadings of this topic, gendered keywords are far from negligible. Indeed, a total of five weakly gendered themes (school, care, household, children, famili) and a strong one (women) emerge within this topic. The implication is that while the saliency of gender equality may be indeed limited especially in comparison to primary concerns such as digitalization, greening and inclusion more in general, such a policy area does to an extent peak through in the background. The extent to which such a marginal role - also emerged from the dictionary analysis and the cross-country heterogeneity that leaves gendered themes nearly fully absent in the NRRPs of some Member States - accounts to mainstreaming of gender equality in the recovery is at the very best debatable. Against such findings, the analysis proceeds qualitatively to build a richer narrative of gender gaps, their pandemic evolution and account in the early response along with their space within the NRRPs together with the geographical inequalities across geographical and gender equal fault lines reflected by the chosen Member States.

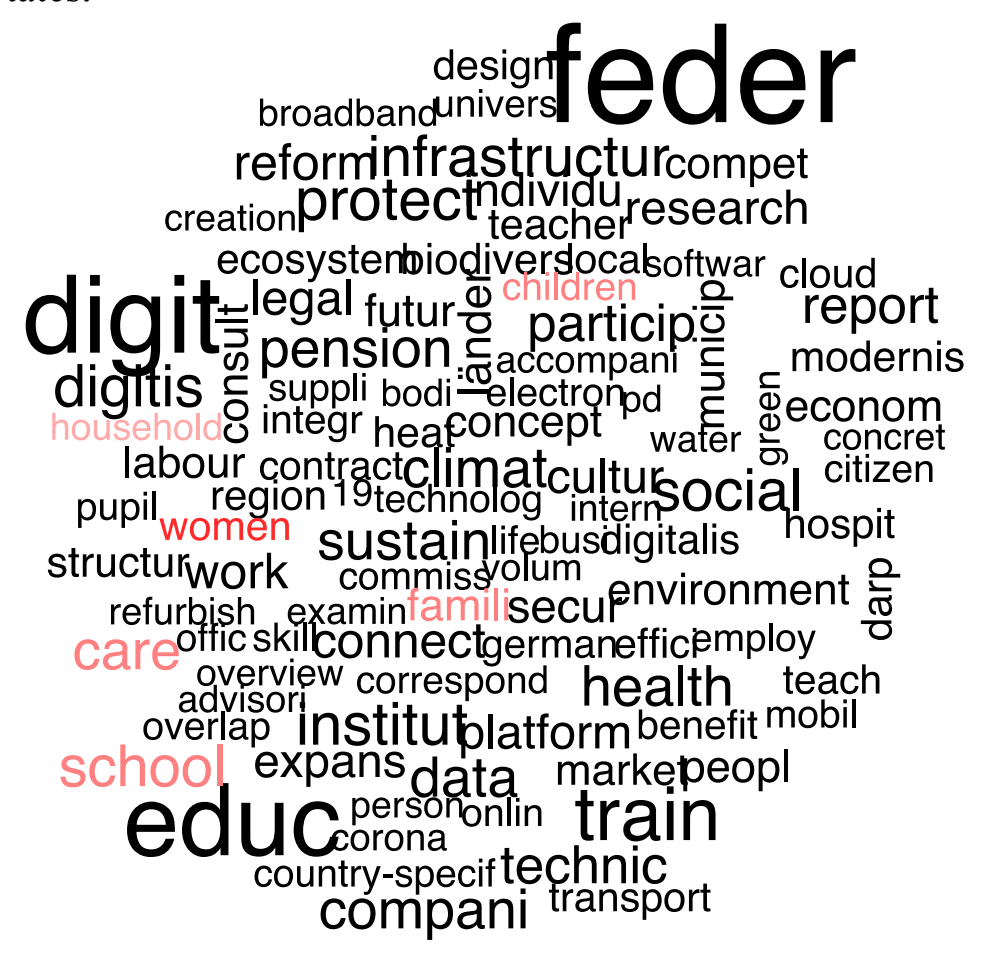

Figure 5 - Word Cloud for most prevalent topic (8)

\subsection{Qualitative analysis of selected countries}

\section{France}

Ahead of the pandemic, the WEF (2019) gender parity ranking placed France 15th worldwide and 10th in Western Europe, within our sample coming third after Spain and Germany. Its remaining gap was scored as $78.1 \%$ overall. Within western Europe, France - having closed $69.1 \%$ of the gap, comes 14th for economic participation (well behind Germany and just ahead of Spain) and 65th worldwide. Conversely, the country is among the top globally for political participation as overall 15th and 8th in Western Europe. Nevertheless, it still comes third within our sample with $45.9 \%$ of the representation gap closed, with only Italy scoring lower. Diving deeper into the within index performance, in the economic arena the country scored quite highly in terms of labor market participation, with $89.1 \%$ of the gap closed with a participation 
rate of $67.5 \%$. Conversely, performance is dismal in terms of the gender pay gap closed only for $52.8 \%$ placing the country 127 th worldwide. Within the household, unpaid work falls disproportionately on women who shoulder on average 1.5 the amount compared to their male counterparts. Against this framework, the country sits in a favorable position comparatively within our sample in demographic terms, with a fertility rate of 1.85 children per woman, paired with generous family policies. In this context, parental leave is generous not only for mothers (42 weeks) but also for fathers (28 weeks).

Against this background, the pandemic response enacted containment choices - such as a proportionally more limited recourse to school closures - which imply a reduced risk for equality than other Member States such as Italy (Ceron et al., 2021). In this framework, gender was also fairly salient in the overall Covid-19 policy mix. A comparative assessment of the saliency of gender in this arena (Ceron and Zarra, 2021) pinpoints shortly under $50 \%$ of measures as catering to mitigation of negative implications for equality. In terms of absolute number of measures, the bulk refers to combating gender-based violence. At the same time, the few economic measures are leave for care for quarantined children and care services for essential workers. The implication is less generous gendered measures of leave and teleworking which is counterbalanced, however, by a strong prioritization of maintaining in-person schooling and childcare. An approach which may be far more beneficial for equality by limiting the additional (generally gendered) work shifting from the market to the household in the context of closures, which even with emergency leave would still force predominantly women albeit temporarily to take a pause from the labor market.

Coming to the NRRP, the country's priorities within the inclusive recovery objective of social resilience are largely concentrated on youth and investment in training services, which constitute, along with health and broadband coverage, the headers under this dimension. From such a perspective, gender is not singled out as a specific or transversal objective per se. The plan has attracted criticism from women interest groups, especially for the gendered implications of predominantly male-dominated sectorial investments, as indicated by a report of Fondation des femmes (2021). More recently, Oxfam (2021) called for a feminist recovery plan, highlighting the equality cost of the pandemic and the need for ambitious measure to revert the trend. Nevertheless, even the Oxfam assessment of the plan identifies 7 out of the 35 billions of the plans as allocated to "feminist" spending, a proportion which far exceeds that of other countries such as Italy - with a larger gap to overcome and devoting the same amount to women, out of over 200 billions in total. Indeed, several measures have positive implications for equality. For instance, educational investment includes the expansion of early-childhood services. Direct measures for employment focus around public recruitment and promotion with explicit benchmarking and targets from a gendered perspective - and subjecting companies to remuneration transparency, a key tool in tackling the gender pay gap, as well as overall disclosure in relation to progress toward equality for entities financed under the plan. The highly focused policy choices of the French plan, despite the lack of a specific heading or transversal prioritization, set their aim on essential elements to support progress toward gender equality, especially in targeting an area of relative weakness compared to the overall ranking of France - the gender pay gap.

\section{Germany}

According to the 2019 report on gender parity issued by the WEF (WEF, 2019), Germany has closed $78.7 \%$ of its gender gap thanks to an improved female participation in the political sphere, with $40 \%$ of female ministers and $30.9 \%$ parliamentarians. The country performs well 
in both educational attainment, where $97.2 \%$ of its gap has been closed, and in health and survival, where it has reached gender parity. Nevertheless, at the economic level, women lag behind in terms of both wages and income, and few of them are in charge in top management roles. Gender parity at work is further hindered by the limited parental leave granted to fathers (only nine weeks). Finally, before Covid-19, the German labor market was characterized by a high share of involuntary temporary female workers (Corti et al, 2021). Similarly to what happened in other countries, the pandemic hit women, especially mothers, more profoundly than men. On average, during lockdown periods, mothers worked fewer hours than before the pandemic, and shouldered more childcare work than fathers (Hipp \& Bünning, 2021).

Most of the gendered policies enacted by the German government in the early outbreak of the pandemic relate to violence prevention. They mostly cover hotline and reporting services, with the guaranteed continuation of the national helpline and a new pharmacy-based reporting system for domestic abuse. In addition, two awareness campaign measures were rolled out with specific information on access to support services through websites and campaigns in supermarkets. Beyond such measures, in May 2020 the government enacted a cash for care program extending support for unpaid care compensation in the absence of services for up to 20 days until September. Paid sick leave and parental leave are the most striking absences in the economic arena, while in the gender-based violence prevention domain Germany is the only country not enacting any police and justice support measures while also being the sole exception to the inclusion of VAW in the Covid-19 response plans.

In this context, the German NRRP aims to achieve gender parity through, among other things, the development of childcare infrastructures and the inclusion of more women in apical roles (e.g. in boards of directors of listed companies). In 2020, the federal government launched a national strategy for gender equality encompassing nine goals, ${ }^{6}$ that range from female empowerment in STEM to active recruitment of women in academia. In addition, a new law obliges listed companies with more than three board members to include at least one woman (WEF, 2021).

\section{Italy}

The country was the one lagging the most behind ahead of the Covid-19 crisis in terms of gender equality within our sample. The WEF (2019) classification placed it as 77th worldwide, with a gap closed only for $70.7 \%$. Within Western Europe, only three Southern EU countries scored lower (Greece, Cyprus and Malta) joined by just the Czech Republic and Hungary within the EU27. In terms of economic empowerment, the country scores the lowest in Western Europe and within the Union, coming 117th out of 153 worldwide. Indeed even in the economic domain, Italy has only closed $59.5 \%$ of the gender gap. Notably, Italy has even lost ground comparatively in the last decades, downgraded from its 88th place in 2006 . The position of the country in terms of political participation lags less dramatically behind, coming 44th globally and 16th in Western Europe. While its score of $26.7 \%$ shines compared to the worst performers in the bloc - Cyprus, Greece and Malta scoring meager 12.2, 16.4 and 18.4\% respectively - it is at miles of distance not only from the top within our sample (Spain) with $52.7 \%$ but also the third (France) with $45.9 \%$. Within the economic arena, the country scores poorly in terms of women's labor force participation (95th worldwide) which stops at just 55.7\%, implying a gap

\footnotetext{
${ }^{6}$ 1) Enabling independent economic security in the course of life; 2) Strengthen social professions as attractive and permeable careers; 3) Equality policy standards in the digital world of life and work; 4) Compatibility of worry work and labor force; 5) Bringing more women to leadership positions in the economy; 6) Achieving equal participation in democracy; 7) Displace stereotypes from culture and science; 8) Creating a new working culture in the public sector; 9) Making equality the task of the entire government.
} 
closed only by $74.4 \%$. The ranking is even worse for the wage gap - 125 th, undercutting even Italy's overall low placement - where only $52.3 \%$ of the gap has been closed. Overall, those dynamics are reflected in a gender gap in estimated earned income of $56 \%$, which carries substantial implications which exceed gender norms in the allocation of house and care responsibilities within families. Stark inequalities remain also in leadership positions within politics and elsewhere. Against this background, the overburden of unpaid work within the household is substantially to the disfavor of women which comparatively dedicate to it 2.34 times the time of their male counterparts. Fertility is at the same time lower than in countries like France, with only 1.33 children per woman and an unmet need for family planning which affects $11 \%$ of women. In the context of childcare, the uneven burden is signaled by a generous maternity leave for women of 47 weeks compared to a mere few days for fathers. As a result, while ranking second for maternity leave, the country comes last for that allocated to men within the sample.

The management of the pandemic has seen gender equality as a salient issue within the political debate. Rather than a sign of attention to the implications of the outbreak for women, the centrality marks quite the opposite. Indeed, women organizations resorted to petitions to guarantee any representation among decision-makers entrusted with advising in the management of the emergency. In parallel, and congruently with pre-existing gaps, the country is over-represented in containment measures such as school closures and lockdowns exposing women to increased risks of detachment from the labor market and partner violence (Ceron and Zarra, 2021). Reconciling work and care came indeed as a challenge, especially in the early phase of the pandemic as schools remained closed until September 2020 (Ceron et al., 2020). From such a perspective, measures opted primarily to facilitate telework for parents of young children, introducing as well complementary support in the form of Covid-19 parental leave a substantial improvement given the gendered track record in Italy - and financial support for those unable to work remotely, with increased generosity for essential workers (Ceron and Palermo, 2020). A comparative assessment of gender sensitive measures in responses to the pandemic in the initial phase (Ceron and Zarra, 2020) ranks the country quite poorly, with only one third of the tracked measures accounting for the mitigation of gendered implications of the crisis. Beyond the tow above mentioned measures of leave and cash for care, violence against women was explicitly included in the Covid-19 response plan and ad-hoc reporting facilitation measures introduced (Ceron and Zarra, 2020).

Against this problematic backdrop in terms of track record for gender equality, contestation emerged also in relation to the recovery plan, with organized campaigns enacted by women interest groups to mainstream gender into the Italian NRRP. Against an initial proposal which was widely assessed as dismal in terms of its prioritization of gender, campaigns such as "Il giusto Mezzo" and "Half of It" devoted to gender equality, highlighting especially the need for improved and geographically even access to childcare services. In such a context, from nearly non-existent, gender became more salient in the evolution of the Italian NRRP from the initial guidelines of the Conte government, its draft and, especially, the final revision under the changed government lead by Draghi. In this context, gender has made its way into the plan as a transversal priority along with youth and geographical cohesion in the South of the country. Such a move parallels the announcement of a strategy for gender equality for the 2021-2026 period which was presented in the summer of 2021 by the government (Boccia, 2021). Within the NRRP, the measures in

\footnotetext{
${ }^{7}$ Le proposte del Giusto mezzo https://ilgiustomezzo.it/wp-content/uploads/2021/03/le-proposte-del-giustomezzo.pdf

${ }^{8}$ Half of it Manifesto https://www.halfofit.it/wp-content/uploads/2021/02/manifesto_completo.pdf
} 
support of parity focus mainly on employment both directly (e.g. support for female entrepreneurship) and indirectly (e.g. expansion of care services). Care services and the activation of NEETS (which overlaps with priorities concerning young people in general rather than specific addressing parity) are the voices making up the largest share of the gendered funding within the plan. The distribution over time of investment in care services, however, peaks in 2023, while dedicating 650 millions in 2021 (Camera dei Deputati, 2021) - a figure far from sufficient to bridge the demand gap or the limited supply especially in the South of Europe.

From such a perspective, while gender may have been far from a minor concern within the policy debate, the albeit improved attention to equality may largely be considered unsatisfactory. Gendered measures, indeed, only account for 7 billions out of the over 200 of the recovery plan, as proudly announced by the Prime Minister Mario Draghi (LaRepubblica, 2020). Far less than the half of the pie advocated for by gendered interest groups whose advocacy is already arguably to thank for the partial progress over the life course of the drafting of the plan. The benchmark is the gendered impact of the pandemic, with women accounting for nearly $73 \%$ of the job-loss in Italy in 2020, reporting shouldering the majority of care and house-work during the first wave of the pandemic and facing a $72 \%$ increase in calls to violence helplines (European Parliament, 2021; Del Boca et al., 2020). The picture is hence that of one of the countries lagging the most behind in equality in the EU ahead of the pandemic, seeing women face a disproportionate high price from the Covid-19 crisis, struggling to account for gendered implication in the early response to the pandemic (e.g. extensive school closures) and giving an underwhelming space to parity in its NRRPs, not without a vocal nudge from gendered interest groups nonetheless.

\section{Spain}

Before the pandemic, Spain had improved significantly in reducing its gender gap. The WEF report (2019) points out that in the last few years, the country has jumped from the 29th position to the 9th, entering the top 10 of the most equal countries worldwide. Such advancement has been mainly due to a substantial gain in the area of political empowerment, where the country has closed its gap in women's representation in institutional settings thanks to a wider participation of women in the political sphere, with around $65 \%$ of female ministers and an almost equal share of female and male members in the parliament. However, the gap is far from closed when it comes to female employment rate, which is well below the EU average, and participation in the workforce and women representation in managerial positions, where marked inequalities persist. In addition, the gap in their participation in STEM studies has widened.

When it comes to Spain's response during the initial phase of the pandemic, above half of the measures adopted were gender sensitive, the highest proportion across the four countries (Ceron and Zarra, 2021). While the majority of measures were devoted to violence prevention, social protection and labor market policies were also adopted (e.g. teleworking) to reduce working hours and reconcile care responsibilities. Among social protection measures it is worth mentioning i) the parental leave, ii) cash for care when hit by school and care centers closures and iii) cash transfers with a 100 euro increase for each minor in the Guaranteed Minimum Income scheme introduced to mitigate the Covid-19 shock. Violence prevention measures are split across strengthening existing services (e.g. hotlines, psychological support via instant messaging), awareness raising campaigns and integration of VAW in Covid-19 response plans. 
Finally, Spain integrated VAW concerns in their pandemic response including a specific contingency plan for gender-based violence during the outbreak.

With regard to the Spanish NRRP, as shown in the text analysis, compared to other countries, gender parity plays a significant role among the priorities set forth by the government. Gender equality is the fourth pillar listed among the measures to be implemented through the EU funds. In particular, Spain aims to boost women employment rate, rearrange the care system, invest in education and reduce the gender digital divide by promoting digital training for women through upskilling and reskilling. Women entrepreneurship is also listed among the key points of the plan, together with investments in childcare facilities and in the care economy. The implementation of reforms in the field of education is particularly prominent in the Spanish NRRP, which promises to close the gap through training in the STEM sectors, the acquisition of digital skills and vocational training. In addition, the launch of an employment plan for women will enhance female active participation in the labor market, with a special focus on addressing the gender gap in rural areas. Furthermore, the gender dimension will be embedded in all the administrative procedures developed in the framework of reforms, as well as in the process of information collection and analysis. Special attention is devoted to public procurement and public administrations, where gender impact assessments will be carried out. Finally, it is worth mentioning complementary actions that foster women's participation in the workforce, namely the modernization of care facilities and social services.

\section{Preliminary conclusions}

The work has pinpointed first the gendered implications of the pandemic, then highlighting how the NRRPs constitute well defined cases for cross-country comparison of the saliency given to equality in the recovery across the EU27. The mixed-methods approach complementing quantitative text analysis with case studies of selected Member States allows for a comprehensive coverage of the Union, without sacrificing evaluating the robustness of overall patterns to a nuanced country-level comparison of pre-pandemic conditions, Covid-19 responses and NRRPs gendered evaluation.

The findings support the main argument of limited saliency of gender parity in the response to the pandemic and recovery pathway, with cross-country differences which do retrace failures and successes toward equality in the Member States. The text analysis has shown that, despite being a priority in the assessment of the national plans, gender equality still is relegated to the background within the analyzed corpus. Especially in a selective approach which includes only unambiguously gendered terms, gender nearly disappears overall and in the majority of Member States. Additionally, heterogeneities are substantial across countries, however, not necessarily fully reflecting traditional North-South-East divides. Indeed, among the best performers, we have a country like Spain, joined by Sweden. Additionally, several northern Member States do not display any gendered features, while several in the East and South of the Union do, albeit weak ones such as school and care. The dictionary analysis recalibrated the gendered claim, especially eastward, when considering a "strict" classification of terms linked to equality. From such a perspective, the parallel between egalitarian societies - and especially those in which women have a strong voice in politics - and the saliency of gender in the NRRP is striking.

The qualitative analysis supports such patterns: countries differ in their mainstreaming of gender within the NRRP in a way which does reflect pre-pandemic parity especially in terms of representation. Italy, with a rocky recent history in terms of parity and systematically sitting 
on the lower end if not bottom of the EU ranking (especially in terms of economic empowerment) had the most disastrous pandemic outcomes from a gendered perspective. Additionally, the underwhelming performance in terms of gendering the NRRP - with only 7 of over 200 billions dedicated to parity - took quite the struggle from women interest group, as equality was especially in early drafts merely an afterthought within the plan, even under the prioritization mandate from the EU level. Key investments such as in care services are limited in scale in comparison to the challenge at hand and delayed in terms of timeline, leaving women - already exiting the labor market en masse during 2020 - hanging for the foreseeable future. The other primary domain, activation policies, is shared with the wider NEET strategy, leaving open the question of its full pertinence to the equality effort. At the opposite side of the spectrum, Spain is the country in which gender lenses are adopted consistently in the plan and mainstreamed into the broader reform program for the post-pandemic reconstruction. While the country has made significant progress in reducing the gap in the last years, the gap still persists in terms of female employment rate and women's participation in the workforce. To cope with such lag, the country has adopted a twofold strategy that should help achieve parity in the medium term. On the one hand, considerable resources will be allocated to education and training, encouraging reskilling and upskilling of women to close the digital divide while pushing for more women in the STEM sectors. On the other hand, investments in the care economy and in childcare infrastructure will boost women employment by lifting their household-related burden. The comparative picture indicates a substantial divide among countries striving for progress and those persistently at the tail end. The other two cases sit in between in terms of prioritization, however, against an undeniably more limited gap to fill compared to Spain and chiefly Italy, especially in the economic arena. Compared to Spain, Germany allocated limited room to gender themes in its NRRP, possibly because of its positive performance in sub-fields such as women's educational attainment. As a consequence, in its NRRP, women's specific provisions refer mainly to gender representation in listed companies, where an obligation for gender quotas in boards of directors has been imposed by law. A similar focused approach takes place in France, which prioritizes tackling the pay gap, leadership in public employment and gender accounting, areas that also reflect the dimension in which the country is comparatively less advanced. A broader implication may be that countries already in a good standing ahead of the crisis may find themselves in a less emergency-driven situation of mitigating the equality disaster of the pandemic and can hence better direct their effort to specific goals and (comparatively) minor weaknesses.

From such a perspective, the work contributes evidence of the bumpy road ahead to mitigate and reverse the damage of Covid-19 to gender parity, as the latter remains a marginal afterthought in the heat of the emergency and - in many countries - in the reconstruction. An even more worrisome pattern, highlighted by our analysis, indicates heterogeneous attention to gendered concerns, generally favoring those countries in which progress economically - and especially politically - had already taken place. On one hand, the finding supports the importance of representation for substantial policy relevance of women's concerns - indicating the pandemic may be a valuable case study also in this domain. On the other, results raise an urgent policy message: they ring the bell of the risk of further growing divides in the progress toward equality, even within the EU, with already problematic countries failing to exploit the recovery to redress gender imbalances. In parallel, it signals how within the framework of the NRRPs and NGEU, supranationally agreed priorities may translate quite differently on the ground at the Member State level. The relevance of the findings in view of the implied limited power of the recovery plan in shaping the reconstruction in the Member States exceeds the boundaries of gender into that of EU policies, especially in the economic domain. A positive message emerges, however, from this analysis: geographical divides need not to align with the 
traditional fault lines between North and South of Europe, leaving the latter perennially behind on many accounts among which notably gender equality. Spain constitutes a success story not only in progress on gender equality, but also in how such developments - in which the country shines especially for political representation - may matter greatly for the saliency of parity even in a context of dire emergency. The implication is that hope should not be lost for those at the backseat of the EU ranking such as Italy: the legacy of heavy societal norms which may imply added challenges for Southern and Eastern countries can be overcome, setting into play a virtuous cycle which supports the improvement of the equality of women. 


\section{References}

Adams-Prassl, A., Boneva, T., Golin, M., \& Rauh, C. (2020). Inequality in the impact of the coronavirus shock: Evidence from real time surveys. Journal of Public Economics, 189, 104245. https://doi.org/10.1016/j.jpubeco.2020.104245

Alon, T., Doepke, M., Olmstead-Rumsey, J., \& Tertilt, M. (2020). The Impact of COVID19 on Gender Equality (No. w26947; p. w26947). National Bureau of Economic Research. https://doi.org/10.3386/w26947

Bertocchi, G. (2020, April 23). COVID-19 susceptibility, women, and work. VoxEU.Org. https://voxeu.org/article/covid-19-susceptibility-women-and-work

Blaskó, Z., Papadimitriou, E., Manca, A. R., European Commission, \& Joint Research Centre. (2020). How will the COVID-19 crisis affect existing gender divides in Europe? https://op.europa.eu/publication/manifestation_identifier/PUB_KJNA30181ENN

Boccia, P. (2021). Ce lo chiede l'Europa? https://www.ingenere.it/articoli/ce-lo-chiedeeuropa

$\begin{array}{lllll}\text { Camera dei } & \text { Deputati. (2020). } & \text { Dossier } & \text { PNRR }\end{array}$ http://documenti.camera.it/leg18/dossier/pdf/DFP28a.pdf

Collins, C., Landivar, L. C., Ruppanner, L., \& Scarborough, W. J. (2020). COVID-19 and the gender gap in work hours. Gender, Work \& Organization, gwao.12506. https://doi.org/10.1111/gwao.12506

Cowan, B.W. (2020) 'Short-run effects of COVID-19 on U.S. worker transitions', NBER Working Paper 27315: 1-16

COM/2020/152 final. Communication From The Commission To The European Parliament, The Council, The European Economic And Social Committee And The Committee Of The Regions A Union of Equality: Gender Equality Strategy 20202025

Corti, F., Núñez Ferrer, J., Ruiz de la Ossa, T. \& Regazzoni, P. (2021). Comparing and assessing recovery and resilience plans - Italy, Germany, Spain, France, Portugal and Slovakia. CEPS Recovery and Resilience Reflection Project. https://www.ceps.eu/ceps-publications/comparing-and-assessing-recovery-andresilience-plans/

Czymara, C. S., Langenkamp, A., \& Cano, T. (2020). Cause for concerns: Gender inequality in experiencing the COVID-19 lockdown in Germany. European Societies, 1-14.

de Vries, E., Schoonvelde, M., \& Schumacher, G. (2018). No Longer Lost in Translation: Evidence that Google Translate Works for Comparative Bag-of-Words Text 
APSA 2021 - Gender and Decision-Making

Applications. Political Analysis, 26(4), 417-430. https://doi.org/10.1017/pan.2018.26

Del Boca, D., Oggero, N., Profeta, P., \& Rossi, M. (2020). Women's and men's work, housework and childcare, before and during COVID-19. Review of Economics of the Household, 18(4), 1001-1017.

EIGE. (2020). Covid-19 wave of violence against women shows EU countries still lack proper safeguards. European Institute for Gender Equality. Retrieved December 30, 2020, from https://eige.europa.eu/news/covid-19-wave-violence-against-womenshows-eu-countries-still-lack-proper-safeguards

European Parliament. (2021). COVID-19 and its economic impact on women and women's poverty

Farre, L., Fawaz, Y., Gonzalez, L., \& Graves, J. (2020). How the Covid-19 Lockdown Affected Gender Inequality in Paid and Unpaid Work in Spain (SSRN Scholarly Paper ID 3643198). Social Science Research Network. https://papers.ssrn.com/abstract $=3643198$

Fondation des Femmes. (2021). [COMMUNIQUÉ DE PRESSE] "RAPPORT : COVID19, CRISE, RELANCE ET EMPLOI DES FEMMES : LA FONDATION DES FEMMES TIRE LA SONNETTE D'ALARME". https://fondationdesfemmes.org/actualites/communique-de-presse-rapport-impactdu-covid-sur-lemploi-des-femmes/

Frodermann, C., Grunau, P., Haepp, T., Mackeben, J., Ruf, K., Steffes, S. and Wanger, S. (2020) 'Wie Corona den Arbeitsalltag verändert hat', IAB-Kurzbericht 13: 1-12.

Galasso, V., Pons, V., Profeta, P., Becher, M., Brouard, S., \& Foucault, M. (2020). Gender differences in COVID-19 attitudes and behavior: Panel evidence from eight countries. Proceedings of the National Academy of Sciences, 117(44), 27285-27291.

Hipp, Lena, and Mareike Bünning. (2021). Parenthood as a Driver of Increased Gender Inequality during COVID-19? Exploratory Evidence from Germany. European Societies 23(sup1): S658-73.

Hupkau, C., \& Petrongolo, B. (2020). Work, care and gender during the Covid-19 crisis.

Kristal, T., \& Yaish, M. (2020). Does the coronavirus pandemic level the gender inequality curve? (It doesn't). Research in Social Stratification and Mobility, 68, 100520. https://doi.org/10.1016/j.rssm.2020.100520

LaRepubblica. (2020). Draghi: "L'Italia punta a investire 7 miliardi entro il 2026 per promuovere la parità di genere. https://www.repubblica.it/economia/2021/06/21/news/draghi_1 italia punta_a inves tire 7 miliardi entro il 2026 per promuovere la parita di genere -307024571/

Lucas, C., Nielsen, R. A., Roberts, M. E., Stewart, B. M., Storer, A., \& Tingley, D. (2015). Computer-Assisted Text Analysis for Comparative Politics. Political Analysis, 23(2), 254-277. https://doi.org/10.1093/pan/mpu019 
Mongey, S., \& Weinberg, A. (2020). Characteristics of workers in low work-from-home and high personal-proximity occupations. Becker Friedman Institute for Economic White Paper.

Montenovo, L., Jiang, X., Rojas, F. L., Schmutte, I. M., Simon, K. I., Weinberg, B. A., \& Wing, C. (2020). Determinants of disparities in covid-19 job losses (No. w27132). National Bureau of Economic Research.

Mimno, D., \& Lee, M. (2014, October). Low-dimensional embeddings for interpretable anchor-based topic inference. In Proceedings of the 2014 Conference on Empirical Methods in Natural Language Processing (EMNLP) (pp. 1319-1328).

Oxfam. (2021). Pour un plan de relance féministe! https://www.oxfamfrance.org/wpcontent/uploads/2021/06/BRIEF-Pour-un-plan-de-relance-feministe_VF.pdf

Rauh, C., Bes, B. J., \& Schoonvelde, M. (2020). Undermining, defusing or defending European integration? Assessing public communication of European executives in times of EU politicisation. European Journal of Political Research, 59(2), 397-423. https://doi.org/10.1111/1475-6765.12350

Reber, U. (2019). Overcoming Language Barriers: Assessing the Potential of Machine Translation and Topic Modeling for the Comparative Analysis of Multilingual Text Corpora. Communication Methods and Measures, 13(2), 102-125. https://doi.org/10.1080/19312458.2018.1555798

Reichelt, M., Makovi, K., \& Sargsyan, A. (2020). The impact of COVID-19 on gender inequality in the labor market and gender-role attitudes. European Societies, 1-18. https://doi.org/10.1080/14616696.2020.1823010

Regulation (EU) 2021/241 of the European Parliament and of the Council of 12 February 2021 establishing the Recovery and Resilience Facility

Roberts, Margaret E et al. (2014). Structural Topic Models for Open-ended Survey Responses. American Journal of Political Science 58(4): 1064-82.

Roberts, Margaret E, Brandon M Stewart, and Dustin Tingley. (2019). Stm: An R Package for Structural Topic Models. Journal of Statistical Software 91(1): 1-40.

Sevilla, A. and Smith, S. (2020) 'Baby steps: the gender division of childcare during the Covid-19 pandemic', IZA Discussion Paper 13302: 1-29.

Traber, D., Schoonvelde, M., \& Schumacher, G. (2020). Errors have been made, others will be blamed: Issue engagement and blame shifting in prime minister speeches during the economic crisis in Europe. European Journal of Political Research, 59(1), 45-67. https://doi.org/10.1111/1475-6765.12340

United Nations Development Programme. (2020). Tackling Social Norms: A game Changer for Gender Inequalities. UN. https://doi.org/10.18356/ff6018a7-en

WEF. (2021). German Parliament Legislation to Improve Gender Parity in Boardrooms. World Economic Forum. https://www.weforum.org/agenda/2021/06/germanparliament-women-quota-company-boards-gender-parity/ 
APSA 2021 - Gender and Decision-Making

WEF. (2021). Global Gender Gap Report 2021 https://www.weforum.org/reports/ab6795a1-960c$\underline{42 \mathrm{~b} 2-\mathrm{b} 3 \mathrm{~d} 5-587 \mathrm{eccda} 6023}$

WEF. (2019) The Global Gender Gap Report 2020. https://www.weforum.org/reports/global-gender-gap-report-2020. 
APSA 2021 - Gender and Decision-Making

\section{Annex}

Table A1 - Summary of the corpus

\begin{tabular}{|c|c|c|c|c|c|c|c|c|}
\hline 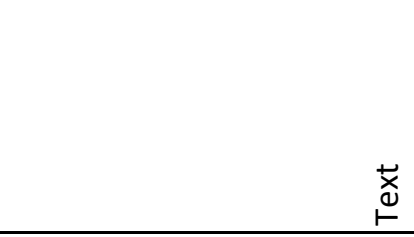 & $\stackrel{\mathscr{\Perp}}{\beth}$ & $\begin{array}{l}\frac{n}{\bar{d}} \\
\frac{\overline{0}}{0} \\
-\end{array}$ & 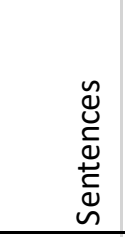 & . & 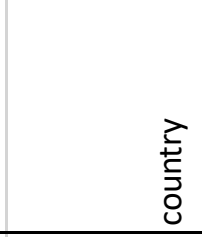 & 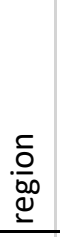 & 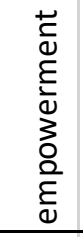 & 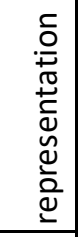 \\
\hline 1_Austria_EN_1.docx & 4135 & 26320 & 852 & 1 & Austria & 1 & 0.67 & 0.47 \\
\hline 1_Austria_EN_2.docx & 10866 & 169891 & 5438 & 1 & Austria & 1 & 0.67 & 0.47 \\
\hline 2_Belgium_EN_1.docx & 13267 & 280410 & 8729 & 2 & Belgium & 1 & 0.71 & 0.48 \\
\hline 3_Bulgaria_EN_1.docx & 7447 & 102954 & 2179 & 3 & Bulgaria & 3 & 0.74 & 0.28 \\
\hline 4_Croatia_EN_1.docx & 17648 & 616225 & 17945 & 4 & Croatia & 3 & 0.67 & 0.29 \\
\hline 5_Cyprus_EN_1.docx & 19518 & 422325 & 11044 & 5 & Cyprus & 2 & 0.69 & 0.18 \\
\hline 6_Czechia_EN_1.docx & 6032 & 76459 & 2120 & 6 & Czechia & 3 & 0.66 & 0.20 \\
\hline 7_Denmark_EN_1.docx & 8823 & 140479 & 5211 & 7 & Denmark & 1 & 0.74 & 0.37 \\
\hline 8_Finland_EN_1.docx & 12770 & 215261 & 7423 & 8 & Finland & 1 & 0.81 & 0.67 \\
\hline 9_France_EN_1.docx & 14436 & 328001 & 7362 & 9 & France & 1 & 0.71 & 0.46 \\
\hline 10_Germany_EN_1.docx & 2820 & 13940 & 187 & 10 & Germany & 1 & 0.71 & 0.51 \\
\hline 10_Germany_EN_201.docx & 3078 & 19645 & 328 & 10 & Germany & 1 & 0.71 & 0.51 \\
\hline 10_Germany_EN_202.docx & 2934 & 21457 & 712 & 10 & Germany & 1 & 0.71 & 0.51 \\
\hline 10_Germany_EN_203.docx & 3482 & 19592 & 364 & 10 & Germany & 1 & 0.71 & 0.51 \\
\hline 10_Germany_EN_204.docx & 4341 & 30458 & 466 & 10 & Germany & 1 & 0.71 & 0.51 \\
\hline 10_Germany_EN_205.docx & 4782 & 36002 & 633 & 10 & Germany & 1 & 0.71 & 0.51 \\
\hline 10_Germany_EN_206.docx & 3506 & 23843 & 384 & 10 & Germany & 1 & 0.71 & 0.51 \\
\hline 10_Germany_EN_207.docx & 4352 & 32070 & 620 & 10 & Germany & 1 & 0.71 & 0.51 \\
\hline 10_Germany_EN_208.docx & 2778 & 16016 & 278 & 10 & Germany & 1 & 0.71 & 0.51 \\
\hline 10_Germany_EN_209.docx & 3865 & 21859 & 381 & 10 & Germany & 1 & 0.71 & 0.51 \\
\hline 10_Germany_EN_210.docx & 3193 & 18585 & 383 & 10 & Germany & 1 & 0.71 & 0.51 \\
\hline 10_Germany_EN_3.docx & 2726 & 15381 & 237 & 10 & Germany & 1 & 0.71 & 0.51 \\
\hline 11_Greece_EN_1.docx & 2715 & 20671 & 608 & 11 & Greece & 2 & 0.67 & 0.12 \\
\hline 11_Greece_EN_2.docx & 5920 & 76861 & 2013 & 11 & Greece & 2 & 0.67 & 0.12 \\
\hline 12_Hungary_EN_1.docx & 11098 & 182803 & 5197 & 12 & Hungary & 3 & 0.67 & 0.11 \\
\hline 13_Ireland_EN_1.docx & 2509 & 14025 & 397 & 13 & Ireland & 1 & 0.73 & 0.50 \\
\hline 14_Italy_EN_1.docx & 10630 & 117893 & 1487 & 14 & Italy & 2 & 0.61 & 0.31 \\
\hline 15_Latvia_EN_1.docx & 11005 & 207472 & 4838 & 15 & Latvia & 3 & 0.82 & 0.31 \\
\hline 16_Lithuania_EN_1.docx & 10961 & 222900 & 5760 & 16 & Lithuania & 3 & 0.81 & 0.43 \\
\hline 17_Luxembourg_EN_1.docx & 5068 & 62356 & 1709 & 17 & Luxembourg & 1 & 0.69 & 0.25 \\
\hline 18_Malta_EN_1.docx & 888 & 3264 & 72 & 18 & Malta & 2 & 0.66 & 0.19 \\
\hline 19_Poland_EN_1.docx & 10609 & 284530 & 7777 & 19 & Poland & 3 & 0.71 & 0.17 \\
\hline 20_Portugal_EN_1.docx & 9853 & 143331 & 2678 & 20 & Portugal & 2 & 0.75 & 0.39 \\
\hline 21_Romania_EN_1.docx & 18338 & 508954 & 11558 & 21 & Romania & 3 & 0.72 & 0.10 \\
\hline 22_Slovakia_EN_1.docx & 1288 & 5448 & 76 & 22 & Slovakia & 3 & 0.68 & 0.18 \\
\hline 23_Slovenia_EN_1.docx & 13114 & 348617 & 7423 & 23 & Slovenia & 3 & 0.80 & 0.18 \\
\hline 23_Slovenia_EN_2.docx & 5149 & 116537 & 2911 & 23 & Slovenia & 3 & 0.80 & 0.18 \\
\hline 23_Slovenia_EN_3.docx & 13095 & 171237 & 3432 & 23 & Slovenia & 3 & 0.80 & 0.18 \\
\hline 24_Spain_EN_1.docx & 12143 & 156538 & 2994 & 24 & Spain & 2 & 0.70 & 0.49 \\
\hline 25_Sweden_EN_1.docx & 6592 & 121596 & 4369 & 25 & Sweden & 1 & 0.81 & 0.52 \\
\hline Total & 307774 & 5412206 & 138575 & & & & 0.72 & 0.37 \\
\hline
\end{tabular}


APSA 2021 - Gender and Decision-Making

\section{Diagnostic Values by Number of Topics}

Held-Out Likelihood

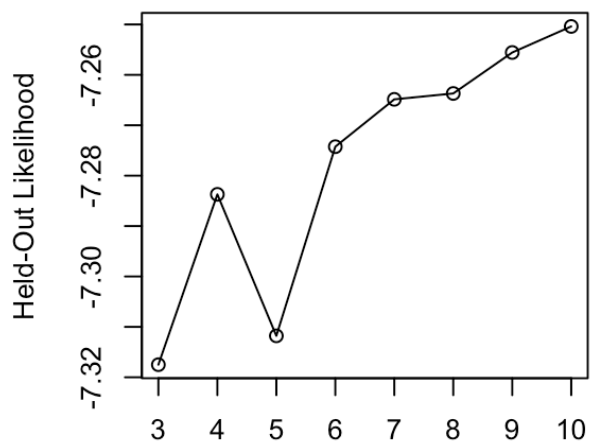

Number of Topics (K)

Semantic Coherence

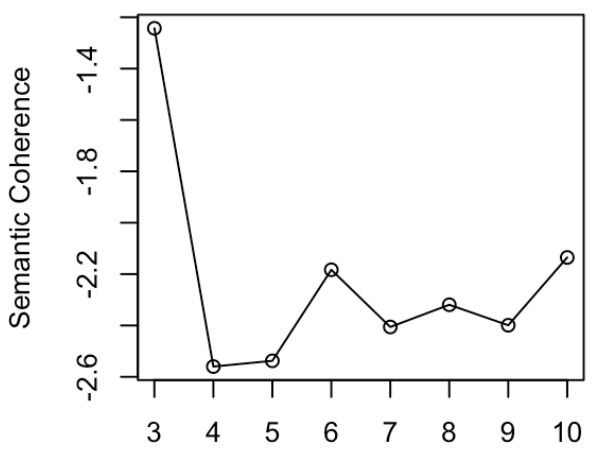

Number of Topics (K)
Residuals

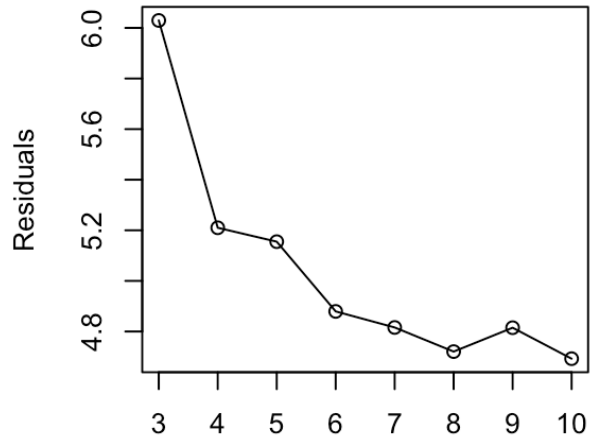

Number of Topics (K)

Lower Bound

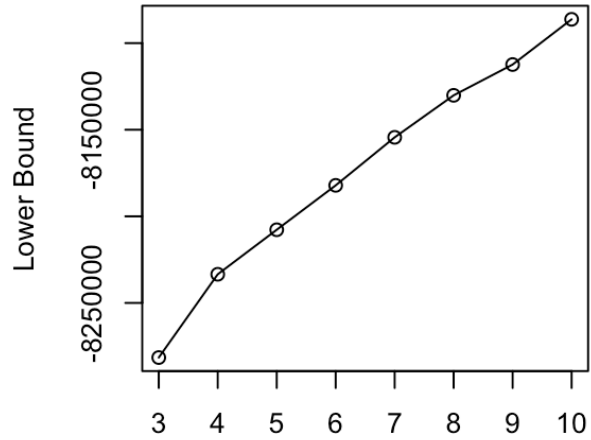

Number of Topics (K)

Figure A1 - STM diagnostics 
Table A2 - Gendered keywords for the dictionary analysis

\begin{tabular}{|c|c|c|c|c|c|c|c|c|c|}
\hline women & covid-19 & access & gender & health & violenc & care & work & impact & risk \\
\hline 405 & 361 & 265 & 245 & 204 & 163 & 144 & 138 & 131 & 129 \\
\hline domest & worker & data & polici & crisi & report & equal & pandem & men & servic \\
\hline 103 & 99 & 98 & 94 & 88 & 82 & 78 & 78 & 75 & 75 \\
\hline healthcar & right & infect & includ & lockdown & home & econom & employ & global & state \\
\hline 74 & 73 & 66 & 64 & 61 & 58 & 57 & 54 & 51 & 47 \\
\hline period & sector & parent & famili & figur & mental & labour & chang & plan & measur \\
\hline 47 & 46 & 46 & 46 & 45 & 44 & 43 & 43 & 43 & 42 \\
\hline depart & childcar & sexual & concern & nation & outbreak & support & constitut & respons & signific \\
\hline 42 & 42 & 41 & 41 & 40 & 39 & 39 & 39 & 38 & 38 \\
\hline particular & countri & coronavirus & peopl & live & protect & public & citizen & affair & femal \\
\hline 38 & 38 & 38 & 38 & 38 & 37 & 37 & 37 & 37 & 36 \\
\hline social & group & communiti & job & govern & level & reduc & time & post-crisi & covid \\
\hline 36 & 36 & 36 & 35 & 35 & 34 & 34 & 34 & 34 & 34 \\
\hline develop & children & household & diseas & disproportior & r differ & germani & abort & eig & reproduct \\
\hline 33 & 33 & 33 & 33 & 32 & 32 & 32 & 32 & 32 & 31 \\
\hline addit & research & sex & must & greater & world & economi & unpaid & case & poverti \\
\hline 31 & 31 & 30 & 29 & 29 & 28 & 27 & 27 & 27 & 26 \\
\hline burden & Igbti & organ & vulner & popul & intern & contracept & import & paid & leav \\
\hline 25 & 25 & 25 & 24 & 24 & 24 & 24 & 23 & 23 & 23 \\
\hline provis & number & death & activ & implement & disabl & age & mother & inequ & societi \\
\hline 23 & 23 & 23 & 22 & 22 & 22 & 22 & 22 & 21 & 21 \\
\hline pay & outcom & hospit & key & black & compar & singl & onlin & financi & ethnic \\
\hline 21 & 21 & 20 & 20 & 20 & 20 & 19 & 19 & 19 & 19 \\
\hline disaggreg & elder & expos & workforc & school & person & ebola & individu & challeng & expect \\
\hline 19 & 18 & 18 & 18 & 18 & 18 & 18 & 18 & 17 & 17 \\
\hline quarantin & futur & role & scienc & male & might & incom & factor & evid & resili \\
\hline 17 & 17 & 17 & 17 & 17 & 17 & 17 & 17 & 16 & 16 \\
\hline unit & matern & trend & secur & pose & restrict & open & statist & ireland & prevent \\
\hline 16 & 16 & 16 & 16 & 16 & 16 & 16 & 16 & 16 & 15 \\
\hline take & abus & problem & repres & review & system & roma & partner & exposur & mortal \\
\hline 15 & 15 & 15 & 15 & 15 & 15 & 15 & 15 & 15 & 15 \\
\hline context & life & girl & lead & gap & consequ & discrimin & rate & committe & frontlin \\
\hline 15 & 15 & 14 & 14 & 14 & 14 & 14 & 14 & 14 & 14 \\
\hline collect & intervent & survey & combat & part & mitig & offer & univers & distribut & occup \\
\hline 14 & 14 & 14 & 13 & 13 & 13 & 13 & 13 & 13 & 13 \\
\hline sever & high & socio-econor & practic & demonstr & recess & resourc & unabl & clinic & suppli \\
\hline 13 & 13 & 13 & 13 & 13 & 13 & 13 & 13 & 13 & 13 \\
\hline victim & assess & virus & divid & safe & demand & transmiss & disrupt & compound & mainstream \\
\hline 12 & 12 & 12 & 12 & 12 & 12 & 12 & 12 & 12 & 11 \\
\hline gender-bas & tackl & place & strategi & facil & psycholog & stress & physic & beyond & unemploy \\
\hline 11 & 11 & 11 & 11 & 11 & 11 & 11 & 11 & 11 & 11 \\
\hline incid & previous & feminis & acut & predomin & estim & anxieti & closur & either & educ \\
\hline 11 & 11 & 11 & 11 & 11 & 11 & 11 & 11 & 11 & 11 \\
\hline exampl & similar & earli & exist & share & precari & assist & posit & sustain & area \\
\hline 11 & 11 & 11 & 10 & 10 & 10 & 10 & 10 & 10 & 10 \\
\hline issu & longer & test & associ & differenti & experienc & intersect & effort & document & extend \\
\hline 10 & 10 & 10 & 10 & 10 & 10 & 10 & 10 & 10 & 10 \\
\hline downstream & routin & forc & identifi & consider & experi & food & medic & market & essenti \\
\hline 10 & 10 & 10 & 10 & 10 & 10 & 10 & 10 & 9 & 9 \\
\hline opportun & close & focus & condit & harass & flexibl & particip & account & alon & polic \\
\hline 9 & 9 & 9 & 9 & 9 & 9 & 9 & 9 & 9 & 9 \\
\hline parliament & meant & given & sex-disaggre & dual & institut & intim & carer & rais & hotlin \\
\hline 9 & 9 & 9 & 9 & 9 & 9 & 9 & 9 & 9 & 9 \\
\hline tourism & industri & suffer & rapid & van & migrant & region & psychiatri & elimin & reflect \\
\hline 9 & 9 & 9 & 9 & 9 & 9 & 9 & 9 & 8 & 8 \\
\hline child & furthermor & initi & balanc & principl & organis & perpetr & older & crise & sdg \\
\hline 8 & 8 & 8 & 8 & 8 & 8 & 8 & 8 & 8 & 8 \\
\hline young & invis & pattern & redund & occur & abil & move & note & delay & consid \\
\hline 8 & 8 & 8 & 8 & 8 & 8 & 8 & 8 & 8 & 8 \\
\hline
\end{tabular}


Table A3 - Gendered features within top 200 across all NRRPs

\begin{tabular}{|c|c|c|c|c|c|c|c|c|c|}
\hline digit & reform & energi & educ & infrastructur & social & health & work & train & data \\
\hline 15997 & 14181 & 13044 & 11236 & 10021 & 9091 & 8772 & 8423 & 7895 & 7756 \\
\hline effici & sustain & climat & transport & innov & econom & water & technolog & research & market \\
\hline 7751 & 7734 & 7694 & 7078 & 7018 & 6822 & 6760 & 6739 & 6666 & 6631 \\
\hline institut & transit & environment & employ & busi & green & protect & compani & integr & wast \\
\hline 6228 & 6138 & 6056 & 5979 & 5910 & 5725 & 5622 & 5232 & 4933 & 4844 \\
\hline skill & region & care & labour & environ & peopl & local & industri & transform & emiss \\
\hline 4818 & 4801 & 4680 & 4373 & 4338 & 4018 & 3999 & 3989 & 3734 & 3732 \\
\hline structur & school & competit & electr & natur & compet & person & digitalis & report & secur \\
\hline 3667 & 3518 & 3375 & 3325 & 3301 & 3271 & 3270 & 3223 & 3203 & 3202 \\
\hline growth & intern & connect & renov & particip & modernis & technic & vehicl & circular & contract \\
\hline 3191 & 3185 & 3103 & 3054 & 3003 & 2903 & 2876 & 2753 & 2749 & 2706 \\
\hline hous & mobil & life & intervent & territori & cultur & municip & cooper & design & commiss \\
\hline 2688 & 2687 & 2648 & 2637 & 2623 & 2605 & 2589 & 2567 & 2553 & 2543 \\
\hline profession & legal & individu & job & digitis & creation & feder & futur & popul & benefit \\
\hline 2535 & 2533 & 2516 & 2464 & 2443 & 2424 & 2422 & 2395 & 2382 & 2372 \\
\hline platform & citizen & council & generat & pollut & enterpris & suppli & audit & bodi & societi \\
\hline 2364 & 2345 & 2258 & 2225 & 2216 & 2210 & 2183 & 2149 & 2134 & 2116 \\
\hline tourism & upgrad & communiti & road & ecosystem & agricultur & urban & electron & equal & hospit \\
\hline 2105 & 2105 & 2097 & 2045 & 1980 & 1957 & 1939 & 1915 & 1901 & 1866 \\
\hline knowledg & heat & employe & purchas & biodivers & consult & disabl & recycl & patient & human \\
\hline 1861 & 1858 & 1842 & 1821 & 1776 & 1761 & 1758 & 1752 & 1750 & 1735 \\
\hline land & treatment & offic & instrument & age & air & staff & gas & inclus & student \\
\hline 1700 & 1693 & 1690 & 1688 & 1688 & 1683 & 1682 & 1669 & 1662 & 1648 \\
\hline univers & hydrogen & medic & young & pension & unemploy & union & railway & women & stakehold \\
\hline 1632 & 1604 & 1601 & 1594 & 1583 & 1556 & 1529 & 1488 & 1486 & 1470 \\
\hline vocat & negat & assist & entiti & right & transfer & capit & deploy & children & associ \\
\hline 1470 & 1460 & 1457 & 1454 & 1447 & 1447 & 1427 & 1421 & 1412 & 1410 \\
\hline greenhous & incom & distribut & cohes & fuel & vat & regulatori & smes & restor & safeti \\
\hline 1376 & 1372 & 1371 & 1366 & 1346 & 1325 & 1321 & 1311 & 1308 & 1289 \\
\hline famili & modern & smart & worker & harm & citi & vulner & scienc & neutral & rail \\
\hline 1286 & 1282 & 1281 & 1275 & 1273 & 1265 & 1261 & 1249 & 1238 & 1221 \\
\hline court & specialis & household & healthcar & transpar & rural & ict & civil & scientif & station \\
\hline 1201 & 1200 & 1193 & 1187 & 1176 & 1174 & 1149 & 1148 & 1120 & 1102 \\
\hline traffic & storag & marin & gender & teacher & decarbonis & code & forest & food & softwar \\
\hline 1095 & 1090 & 1062 & 1058 & 1038 & 1011 & 1007 & 980 & 974 & 968 \\
\hline gap & medicin & plant & custom & loan & save & ecolog & passeng & devic & intellig \\
\hline 966 & 959 & 955 & 934 & 933 & 929 & 905 & 900 & 894 & 892 \\
\hline maintain & stock & compli & onlin & mainten & last & optimis & clear & accompani & close \\
\hline 890 & 882 & 881 & 879 & 877 & 874 & 873 & 871 & 871 & 866 \\
\hline
\end{tabular}


APSA 2021 - Gender and Decision-Making

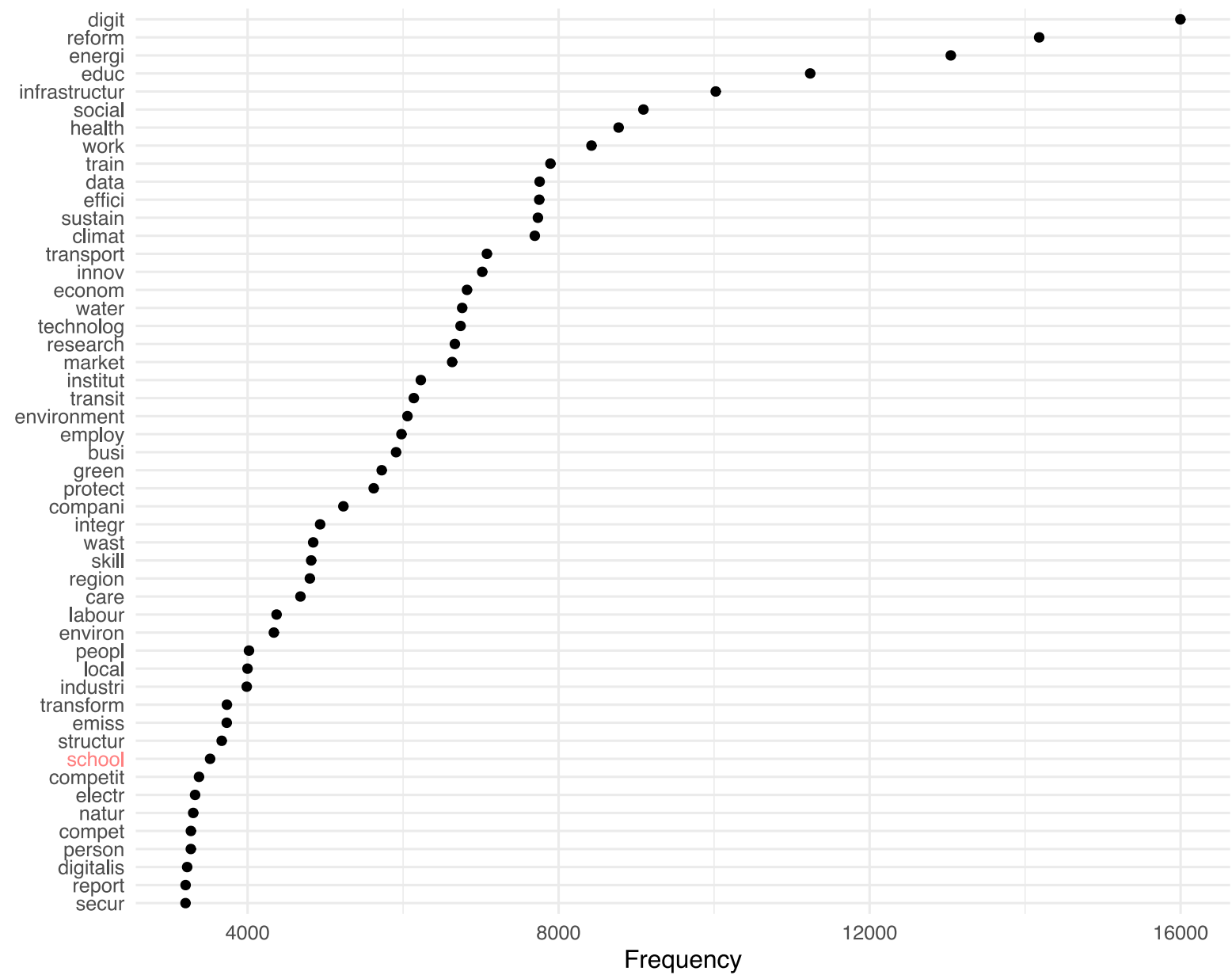

Figure A2 - Top 50 features across all NRRPs 
APSA 2021 - Gender and Decision-Making

Table A4 - Gendered dictionary analysis by country

\begin{tabular}{|c|c|c|c|c|}
\hline & Gender broad & Gender & $\begin{array}{l}\text { Gender broad } \\
\text { (weighted) }\end{array}$ & $\begin{array}{c}\text { Gender } \\
\text { (weighted) }\end{array}$ \\
\hline Austria & 1166 & 288 & $2.66 \%$ & $0.66 \%$ \\
\hline Belgium & 876 & 275 & $1.41 \%$ & $0.44 \%$ \\
\hline Bulgaria & 262 & 85 & $1.23 \%$ & $0.40 \%$ \\
\hline Croatia & 1891 & 532 & $1.48 \%$ & $0.42 \%$ \\
\hline Cyprus & 1354 & 373 & $1.53 \%$ & $0.42 \%$ \\
\hline Czechia & 452 & 178 & $2.79 \%$ & $1.10 \%$ \\
\hline Denmark & 430 & 230 & $1.29 \%$ & $0.69 \%$ \\
\hline Finland & 704 & 234 & $1.51 \%$ & $0.50 \%$ \\
\hline France & 836 & 187 & $1.16 \%$ & $0.26 \%$ \\
\hline Germany & 818 & 283 & $1.36 \%$ & $0.47 \%$ \\
\hline Greece & 511 & 212 & $2.10 \%$ & $0.87 \%$ \\
\hline Hungary & 1136 & 326 & $2.71 \%$ & $0.78 \%$ \\
\hline Ireland & 68 & 33 & $2.04 \%$ & $0.99 \%$ \\
\hline Italy & 805 & 280 & $2.84 \%$ & $0.99 \%$ \\
\hline Latvia & 742 & 220 & $1.74 \%$ & $0.52 \%$ \\
\hline Lithuania & 1077 & 217 & $2.15 \%$ & $0.43 \%$ \\
\hline Luxembourg & 54 & 20 & $0.44 \%$ & $0.16 \%$ \\
\hline Malta & 17 & 6 & $2.03 \%$ & $0.72 \%$ \\
\hline Poland & 1248 & 253 & $1.96 \%$ & $0.40 \%$ \\
\hline Portugal & 630 & 210 & $1.81 \%$ & $0.60 \%$ \\
\hline Romania & 2201 & 460 & $1.94 \%$ & $0.41 \%$ \\
\hline Slovakia & 49 & 3 & $4.01 \%$ & $0.25 \%$ \\
\hline Slovenia & 1600 & 340 & $1.20 \%$ & $0.26 \%$ \\
\hline Spain & 1417 & 886 & $3.80 \%$ & $2.38 \%$ \\
\hline Sweden & 628 & 349 & $2.37 \%$ & $1.32 \%$ \\
\hline
\end{tabular}


APSA 2021 - Gender and Decision-Making

Table A5 - Top 10 highest probability words across the 12 selected topics

\begin{tabular}{|r|l|l|l|l|l|l|}
\hline & V1 & V2 & V3 & V4 & V5 & V6 \\
\hline 1 & work & reform & digit & data & energi & climat \\
\hline 2 & educ & digit & reform & climat & digit & reform \\
\hline 3 & train & educ & social & research & reform & digit \\
\hline 4 & vat & health & energi & vehicl & infrastructur & environment \\
\hline 5 & infrastructur & energi & econom & technolog & data & emiss \\
\hline 6 & digit & infrastructur & sustain & energi & educ & green \\
\hline 7 & data & innov & modernis & industri & effici & energi \\
\hline 8 & energi & institut & transform & innov & work & transit \\
\hline 9 & upgrad & social & train & feder & health & work \\
\hline 10 & research & data & infrastructur & infrastructur & transport & water \\
\hline & V7 & V8 & V9 & V10 & V11 & V12 \\
\hline 1 & educ & feder & digit & digit & digit & water \\
\hline 2 & reform & digit & energi & climat & social & wast \\
\hline 3 & infrastructur & educ & social & transit & train & energi \\
\hline 4 & digit & train & transit & territori & energi & environment \\
\hline 5 & energi & protect & reform & employ & infrastructur & climat \\
\hline 6 & institut & institut & busi & energi & reform & reform \\
\hline 7 & social & social & portug & health & council & protect \\
\hline 8 & transport & digitis & econom & train & data & effici \\
\hline 9 & train & school & educ & neutral & region & infrastructur \\
\hline 10 & intervent & infrastructur & sustain & reform & work & emiss \\
\hline & & & & & \\
\hline
\end{tabular}

